\title{
Climate change impact on future wildfire danger and activity in southern Europe: a review
}

\author{
Jean-luc Dupuy ${ }^{1}$ (D) - Hélène Fargeon ${ }^{1,2}$ • Nicolas Martin-StPaul ${ }^{1} \cdot$ François Pimont ${ }^{1}$ - Julien Ruffault ${ }^{1}$. \\ Mercedes Guijarro $^{3,4}$ - Carmen Hernando ${ }^{3,4}$ - Javier Madrigal ${ }^{3,4}$ • Paulo Fernandes ${ }^{5}$
}

Received: 31 October 2019 / Accepted: 20 February 2020 / Published online: 30 March 2020

(C) INRAE and Springer-Verlag France SAS, part of Springer Nature 2020

\begin{abstract}
- Key message Wildfire danger and burnt areas should increase over the century in southern Europe, owing to climate warming. Fire-prone area expansion to the north and to Mediterranean mountains is a concern, while climate-induced burnt area increase might be limited by fuel availability in the most arid areas. Further studies are needed to both assess and reduce uncertainties on future trends.

- Context Wildfire is the main disturbance in forested ecosystems of southern Europe. Warmer and drier conditions projected in this region are expected to profoundly affect wildfire regimes.

- Aims In this review, we pursue a twofold objective: (i) report the trends in wildfire danger and activity projected under warming climate in southern Europe and (ii) discuss the limitations of these projections.

- Methods We reviewed 23 projection studies that examined future wildfire danger or wildfire activity at local, regional or continental scale.

- Results Under the scenarios with the highest greenhouse gas emissions, we found that projection studies estimate an increase in future fire danger and burnt areas varying, on average, from 2 to $4 \%$ and from 5 to $50 \%$ per decade, respectively. Further comparisons on the magnitude of increase remained challenging because of heterogeneous methodological choices between projection studies. We then described three main sources of uncertainty that may affect the reliability of wildfire projections: climate projections, climate-fire models and the influences of fuels, fire-vegetation feedbacks and human-related factors on the climate-fire relationships.

- Conclusion We suggest research directions to address some of these issues for the purpose of refining fire danger and fire activity projections in southern Europe.
\end{abstract}

Keywords Global warming $\cdot$ Projections $\cdot$ Climate-fire relationship $\cdot$ FWI $\cdot$ Burnt areas $\cdot$ Forest fuels $\cdot$ Mediterranean forests

Handling Editor: Erwin Dreyer

Contribution of the co-authors Paulo Fernandes, Mercedes Guijarro, and Julien Ruffault: contributed to design and writing the paper. Other co-authors: contributed to general drafting of the paper.

Jean-luc Dupuy

Jean-luc.Dupuy@inrae.fr

1 Ecologie des Forêts Méditerranéennes (URFM), INRAE, F-84914 Avignon, France

2 Ministère de l'Agriculture et de l'Alimentation, Paris, France
3 Centro de Investigación Forestal (CIFOR) - Departamento de Dinámica y Gestión Forestal, Instituto Nacional de Investigación y Tecnología Agraria y Alimentaria (INIA), Madrid, Spain

4 Instituto Universitario de Investigación en Gestión Forestal Sostenible, UVa-INIA, Madrid, Spain

5 Centro de Investigação e de Tecnologias Agro-Ambientais e Biológicas, Universidade de Trás-os-Montes e Alto Douro, Quinta de Prados, 5000-801 Vila Real, Portugal 


\section{Introduction}

Wildfires play a key role in the dynamics of Mediterranean forest ecosystems and can have beneficial effects such as opening landscapes and enhancing biodiversity (Keeley et al. 2011). However, the balance between beneficial and detrimental ecological effects of fires depends on several features of fire regimes, basically the frequency and intensity of fire disturbances. Moreover, wildfires threat forest values and ecosystem services, as well as people and human assets, raising the risk issue. In the context of global warming, shifts in fire regimes and future risk need to be anticipated for the adaptation of forest and fire management policies.

Between 2007 and 2016, around 48,000 forest fires burned 457,000 ha as annual average in the five southern European countries most affected by wildfires (Portugal, Spain, France, Italy and Greece) (San-Miguel-Ayanz et al. 2018). While recent statistics show a decrease in fire activity in most of these regions due to changes in land use/land cover or suppression policies (e.g. Turco et al. 2016; Curt and Frejaville 2018; Silva et al. 2019), a number of studies have also shown an increase in fire weather (i.e. daily to seasonal weather conditions conducive to fires) during the same period (Piñol et al. 1998; Pausas 2004; Jolly et al. 2015; Fréjaville and Curt 2015; Ruffault et al. 2016). Moreover, 2017 has been one of the most devastating wildfire seasons on record in some of the southern Mediterranean countries, with a noteworthy increase in burnt area of 535\% for Portugal, 160\% for France, 105\% for Italy and $95 \%$ for Spain, relative to the average values of the previous decade (San-Miguel-Ayanz et al. 2018).

Fuel moisture has long been recognized as a major component of fire danger (Brown and Davis 1973), and components of fire activity such as number of fires or burnt area are known to respond positively to increasing fuel dryness (e.g. Flannigan et al. 2016; Turco et al. 2017). Hence, the increase in temperature and decrease (or stagnation) in summer precipitation that are both projected for southern Europe (Kovats et al. 2014) are expected to increase fire danger and fire activity in this region. Flannigan et al. (2009) reviewed the literature addressing the impact of climate change on wildfires from a global perspective, censing all studies reporting projections of future wildfire danger or activity under global warming scenarios regardless of the spatial scale. At that time, they reported 38 studies mostly conducted at a regional or a national level in North America or Australia. However, only two studies were dedicated to Europe, one addressing landscape vegetation changes under new climatic conditions in Corsica (Mouillot et al. 2002), and the other proposing the first projections of wildfire danger at the scale of southern Europe (Moriondo et al. 2006). There were at that time critical research needs in terms of projections of wildfire danger and activity in Europe. In contrast, in 2019, we found 23 studies reporting such projections from regional to continental scales, suggesting an increasing research effort in Europe on that topic. Accordingly, the general trends for wildfires in Europe have been briefly summarized by the experts of the IPCC in their fifth assessment report (Kovats et al. 2014): 'Future wildfire risk is projected to increase in southern Europe, with an increase in the occurrence of high fire danger days and in fire season length. The annual burnt area is projected to increase by a factor of 3 to 5 in southern Europe compared with the present under the A2 scenario by 2100. In northern Europe, fires are projected to become less frequent due to increased humidity'. Global fire projections, however, show more contrasted results for southern Europe: Scholze et al. (2006) predicted a likely critical increase in wildfire frequency in most regions by the end of the century, Krawchuk et al. (2009) a decrease or stagnation in burn probability, Moritz et al. (2012) a likely but slight increase in burn probability and Flannigan et al. (2013) a 2- to 3-fold increase in fire season severity (i.e. a cumulative rating of the fire control difficulty). This supports a new review, based on the most recent research efforts in Europe and focused on forest fire, to refine such general trends.

In this paper, we review the scientific literature addressing the assessment of climate change impact on future fire danger and activity in southern Europe, including the Iberian Peninsula, France, Italy, Balkans and Greece. The review includes projection studies, as well as studies addressing the understanding and modelling of climate-fire relationships in the European context. In the present paper, a projection study is defined as a study that projects fire danger (indices) or fire activity (fire number, fire size, burnt area) in the forthcoming decades based on climate series simulated under climate change scenario(s) and that explicitly reports future changes in these fire metrics. In the reviewed studies, fire danger was always rated with the Fire Weather Index (FWI) System; therefore, the term 'fire danger' hereinafter refers to the fire weather. Projection studies were tracked starting from year 2000 with the following combination of keywords in the Web of Science: climate change AND (wildfire OR forest fire) $A N D$ (projection OR projected). Among them, we selected the studies that effectively addressed the topic and were conducted in southern Europe, and we considered works published up to July 2019. We did not specifically include global fire projections in the review because they aim to address future changes in fire regimes or emissions at broad geographical scales or biome level, use coarse grid cells (often $>100 \mathrm{~km}$ ) and often do not report rates of change of standard fire metrics. In Sect. 2, we explain why modelling fire activity is challenging and then we give an overview of the models that were used in the reviewed projection studies. In Sect. 3, we present and compare the results of these projections studies and attempt to summarize the main trends. In Sect. 4, we disclose and discuss the limitations of current projections. Finally, we provide a synthetic view of expected trends in future fire danger and 
activity in southern Europe and propose some research directions to improve or complement current projections.

\section{Projection methods}

The basic couplings between climate, vegetation (fuel) and fire processes that drive the impact of climate change on fire activity have been identified, yet modelling climate change impact on wildfire activity remains highly challenging for several reasons. First, fire activity is primarily controlled by fuel continuity and availability (load, spatial structure, moisture), weather conditions (fire weather including wind, temperature, relative humidity, precipitation and atmospheric stability) and ignition sources (lightning or human causes). Biomass production, its availability to burn, fire weather and ignition have been described as a hierarchy of four switches that must be activated for fire to spread (Bradstock 2010). Ignitions and fuels are strongly impacted by human activities and infrastructures, land use and prevention policies. Moreover, fire control operations tend to reduce the size of fires and the resulting burnt area. Hence, fire activity is the result of multiple, possibly interacting or correlated factors acting at different scales. In this respect, projecting fire weather is comparatively straightforward. Second, a main impact of climate on fire activity comes through some changes in the moisture content of fuels (live and dead biomass). This impact is driven by a number of dynamical physical and biological processes involved in the soil-plant-atmosphere functioning at time scales ranging from hours to the season. In particular, water balance (evaporation, precipitation, transpiration, water storage and drainage) largely determines the water content of fuels as well as the production of dead fuel (Jolly and Johnson 2018). Although scientific research has produced representations of such dynamical processes, there are still fundamental and practical limitations to use them to predict fuel moisture (e.g. Jolly et al. 2014; Martin-StPaul et al. 2017; Jolly and Johnson 2018), even for dead fuel (e.g. Matthews 2014). Thus, more simple models are used to describe the climate impact on fires through fuel moisture dynamics, such as empirical fire danger indices or statistical models linking directly fire activity to weather or drought indices (e.g. Flannigan et al. 2016). Third, climate change will impact not only fuel moisture but also fuel load/ continuity and fuel structure, because climate is a major driver of biomass accumulation (through primary production) and vegetation composition and structure (Bradstock 2010). Furthermore, natural disturbances, including fire, affect forest and landscape dynamics, induce strong feedbacks on vegetation and fuels (Seidl et al. 2011). Dynamic Global Vegetation Models (DGVM) are land biogeochemical models representing the climate-soil-vegetation-interacting processes and have been coupled with fire models to study the role of fire in vegetation dynamics and in the terrestrial carbon cycle (Flannigan et al. 2009). These complex DGVM-fire models (Hantson et al.
2016; Rabin et al. 2017) have been used to assess fire activity up to the global scale, as well as the contribution of vegetation fires to carbon emissions to the atmosphere. Predicting how forests and landscapes will change, and in turn how fuels will change, is thus highly challenging and by far exceeds the context of forest fire risk assessment.

Table 1 reports the main characteristics of the 23 projection studies that were reviewed in this paper. Among them, 8 studies were conducted at continental scale, 10 at national scale and 5 at regional or local scale. Thirteen studies considered the A2/RCP8.5 scenario, 11 considered the A1B scenario and few of them other scenarios. Fifteen studies used climate series from only one climate model to represent the future climate. Daily climate datasets were generally used, and spatial resolution was often $25 \mathrm{~km}$, ranging between 10 and $50 \mathrm{~km}$. However, projection studies differed by climate-fire models and projected fire metrics. As detailed hereinafter, they used the FWI System to project fire danger and three other types of climate-fire models to project fire activity (mostly burnt areas), namely statistical-correlative fire models, spatially explicit fire spread models and DGVM-fire models (Fig. 1).

\subsection{Fire Weather Index}

Fourteen projection studies resort to the FWI System, among which 12 studies projected the FWI or its components to rate the fire danger. The FWI System, a worldwide used fire danger rating system, was developed by the Canadian Forest Service and was initially designed for pine fuel types (Van Wagner 1987). The FWI System empirically reflects the mechanistic impact of weather variables on fuel moisture and fire behaviour at daily to monthly time scales (Flannigan et al. 2016). It consists of six components: three moisture indices corresponding to three different fuel response times track the cumulative and dynamic influence of weather conditions on the moisture content of dead fuels (the Fine Fuel Moisture Code, FFMC; the Duff Moisture Code, DMC; and the Drought Code, DC); the other indices describe the potential for fire spread (the Initial Spread Index, ISI), fuel consumption (the Buildup Index, BUI) and fire intensity (Fire Weather Index, FWI), as a combination of the former indices. The indices are calculated daily from noon (12:00 LST) air temperature, relative humidity, wind speed and previous $24-\mathrm{h}$ accumulated precipitation. The FWI System also includes the Seasonal Severity Rating (SSR), which represents fire control difficulty over a season. The SSR is a seasonal average of the Daily Severity Rating (DSR), which is computed from the daily FWI.

\subsection{Statistical-correlative fire models}

Fire activity (mostly burnt area) has been modelled through correlations with the FWI components (studies 3, 22), with the 


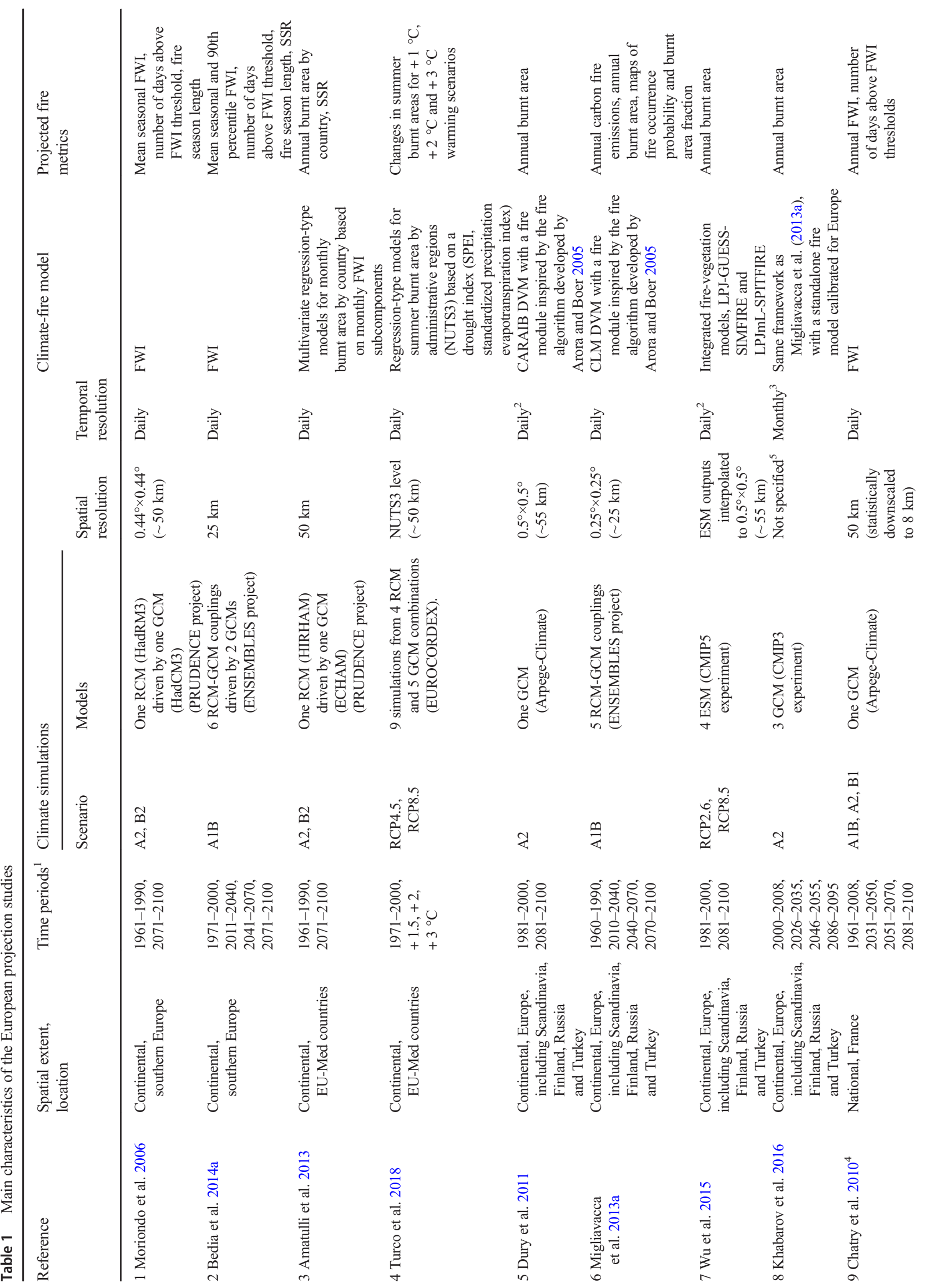




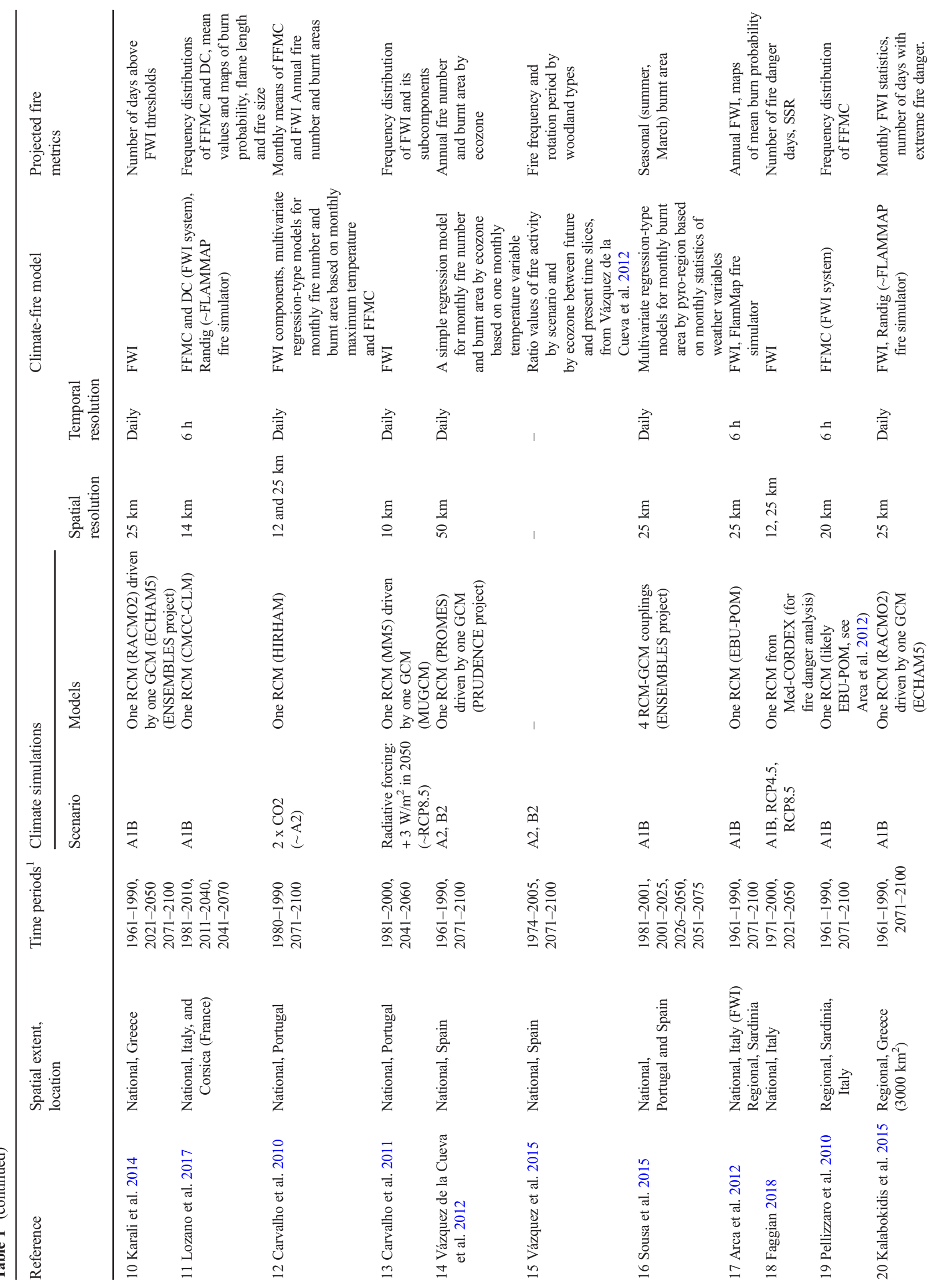

INRAC 토ringer 


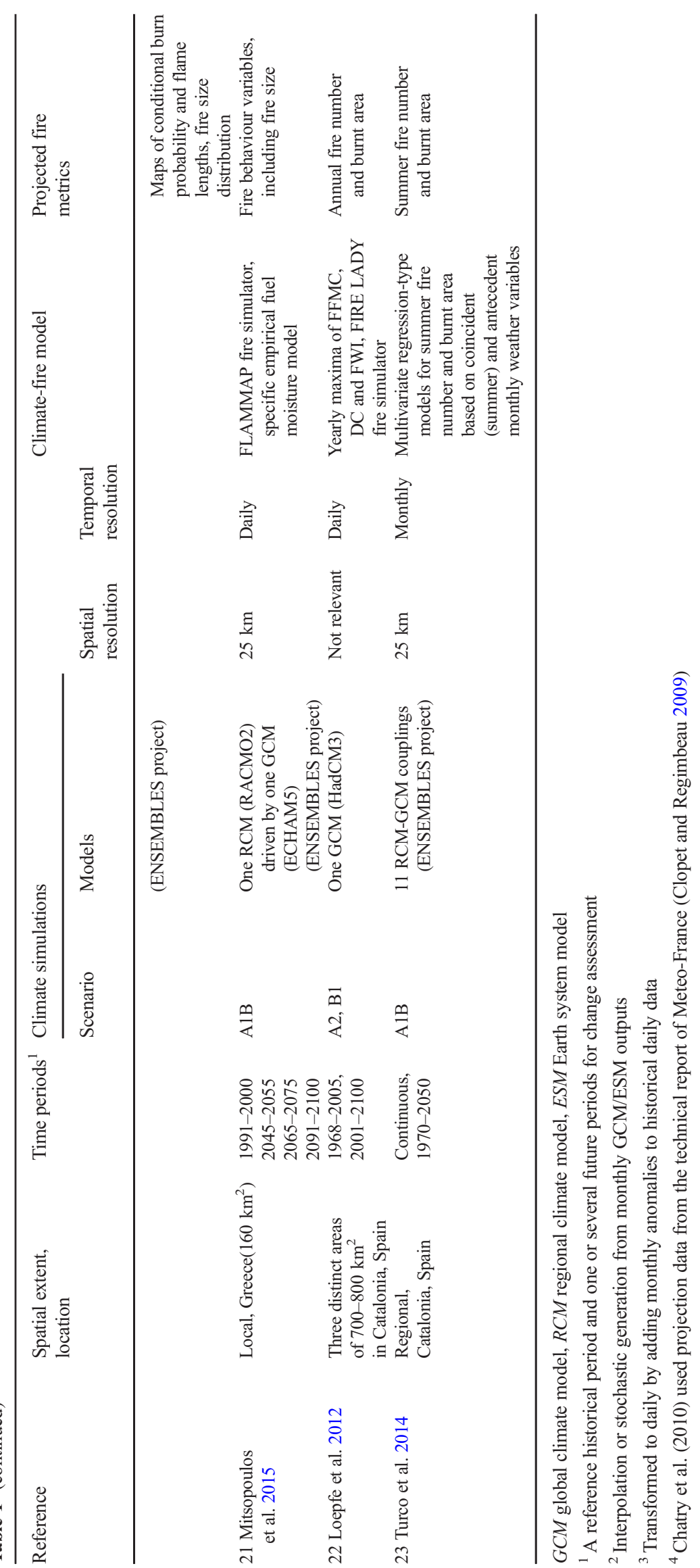


Fig. 1 Conceptual schemes of the climate-fire models used in reviewed projection studies

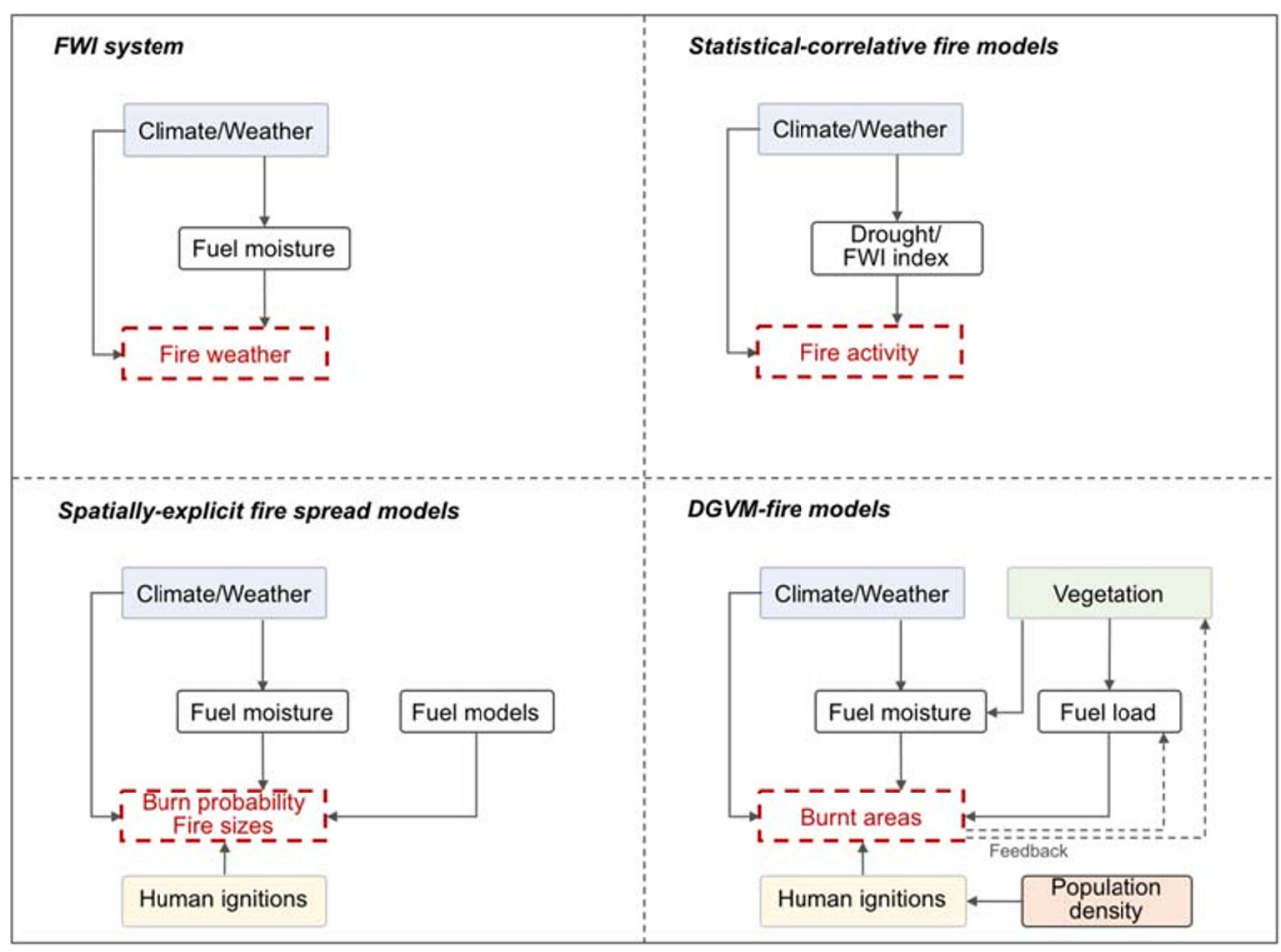

standardized precipitation evaporation index (SPEI, a monthly drought index; Vicente-Serrano et al. 2010) (4), with monthly weather variables $(14,16,23)$ or with both the FFMC and monthly weather variables (12). All models described hereinafter were fitted to the log-transformed number of fires or the log-transformed burnt area, with the exception of Sousa et al. (2015). Carvalho et al. (2010) built a series of statistical linear models for fire number and burnt area as function of the monthly FFMC and maximum temperature for 10 districts of Portugal. Variance explained by the models ranged between 46 and $69 \%$ for fire number and between 58 and $71 \%$ for burnt areas, according to the districts. Vázquez de la Cueva et al. (2012) built a series of statistical linear models for fire number and burnt area as function of a monthly weather variable for 15 ecozones covering Spain. The selected predictor variable was a temperature statistic in all models, but the statistics changed among ecozones, as well as the variances explained by the models that ranged from 20 to $68 \%$ for the fire number and from 12 to $66 \%$ for the burnt area. Sousa et al. (2015) distinguished four pyro-regions (i.e. characterized by four different fire regimes) over the Iberian Peninsula and built a statistical linear model for the inter-annual variations of seasonal (i.e. summer, March depending on the pyro-region) burnt areas in each pyro-region. Selected predictor variables were mostly based on temperature and precipitation data, and were different among pyro-regions. Models explained 52 to $72 \%$ of the variance according to the pyro-region. In Catalonia, Turco et al. (2013b) built linear regression models for summer fire number and burnt area, respectively accounting for up to 91 and $76 \%$ of the observed variance. These models used both coincident (the summer season) and antecedent weather conditions and were the basis for the Turco et al. (2014) projection study. Amatulli et al. (2013) used components of the FWI System as explanatory variables to estimate burnt areas based on three different modelling approaches (regression and machine learning techniques). Models were adjusted for five Euro-Mediterranean countries, namely the Mediterranean France, Greece, Italy, Portugal and Spain, and for the whole area covered by these countries. Components of the FWI System selected as explanatory variables changed according to the country, and the modelling approach showing the best performances explained 43 to $77 \%$ of the variance, $74 \%$ for the whole area. Turco et al. (2018) used multi-month aggregated values of the SPEI drought index as explanatory variables to estimate burnt areas in 44 eco-regions covering the same area as in Amatulli et al. (2013). Correlations between log-transformed burnt areas and SPEI ranged between 0.37 and 0.89 according to eco-region, and sensitivity to SPEI-based values (i.e. regression slope) decreased with the long-term annual mean temperature of the eco-region.

\subsection{Spatially explicit fire spread models}

In this approach (studies $11,17,20,21$ ), fire spread is explicitly simulated across the landscape with a contagion algorithm under specified wind speed and fuel moisture conditions. In the context of future projections, these conditions must be specified from a future climate scenario. In particular, fuel moisture was estimated either from the FFMC and DC codes 
of the FWI (17) or from empirical fuel moisture-weather relationships $(20,21)$. Fire simulations account for topography and for spatial variations in fuels through spatially explicit attribution of fuel models, and provide variables measuring fire behaviour (rate of fire spread, fireline intensity, flame length) and fire activity (burn probability per pixel, fire size). This approach is well-suited for local to regional scales, but has also been applied nationally (11).

\subsection{DGVM-fire models}

Some studies $(5,6,7,8)$ have projected burnt areas with DGVMfire models, namely the CARAIB (5) and CLM-AB DGVM (6, 8) coupled with a fire model inspired in the CETEM model (Arora and Boer 2005), and the LPJ-GUESS-SIMFIRE and LPJmL-SPITFIRE DGVM-fire models both used in the same study (7). Importantly, the physiological processes at play are represented in the DGVMs, which enables the capture of climate and $\mathrm{CO}_{2}$ effects on primary production and gives a basis for the estimation of fuel load dynamics. Except for LPJ-GUESSSIMFIRE, fuel loads are computed from the carbon pools accounting for the aboveground biomass. In SIMFIRE, the annual maximum FAPAR (fraction of vegetation-absorbed photosynthetically active radiation) represents vegetation fractional cover and is used as a proxy for fuel load/continuity. In CARAIB and CLM models, soil moisture dynamics as driven by climate/ weather variations are predicted from the coupling of plant and soil hydrological processes, and soil moisture is used to represent fuel moisture, which in turn conditions fire spread in the fire module. Both LPJ-GUESS and LPJmL DGVM use functions of the Nesterov drought index to represent the effect of fuel moisture on fire. It is calculated using daily temperature, dew point and number of days since the last significant precipitation event. This index is used to compute fuel moisture and a fire danger index that influences both the probability of ignition success and fire spread in SPITFIRE, while the maximum daily Nesterov index is used to calibrate the annual burnt area model in SIMFIRE. An important difference between LPJ-GUESS and LPJmL is that the former represents vegetation based on explicit individuals, whereas the later uses average individuals. It must also be noticed that SPITFIRE is a detailed process-based fire model and includes fire effects (Thonicke et al. 2010), whereas SIMFIRE predicts the fractional burnt area from a simple function of land cover type, mean monthly FAPAR, annual maximum of the Nesterov index and population density, which has to be parameterized from observed burnt areas (Knorr et al. 2013).

\section{Projection results}

A number of factors differ between projection studies, which rendered the systematic comparison of quantitative results quite challenging. This includes the nature and associated statistics (mean, quantile, threshold exceedance) of fire metrics, the climate model(s) and run(s), the socioeconomic scenario(s), the historical and future periods selected for computing present and future metrics, the geographic area and the climate-fire model used to predict the fire metric. For the purpose of study comparison, we report the rates of change of fire danger and fire activity metrics in percentage or days per decade in Table 2 (see Appendix for detailed comments on the reported data).

Table 2 reveals that the number of (apparent) replications of the results is small and that the different scenario/horizon combinations have not been equally explored. Regarding fire danger metrics, data mostly come from the three studies of Moriondo et al. (2006), Bedia et al. (2014a) and Amatulli et al. (2013) at the scale of southern Europe, which all provide results down to national scales. Moriondo et al. (2006) and Bedia et al. (2014a) both report mean seasonal FWI and fire season length, while Amatulli et al. (2013) and Bedia et al. (2014a) report SSR. Four national or regional studies also provide the mean FWI. Regarding fire activity, most studies report burnt areas, whereas fire number or fire size is seldom reported. A single study reports national burnt areas (Amatulli et al. 2013). We provide detailed comments on the results of the studies in Appendix. In the following, we propose a tentative summary of these results.

All studies show future increase in fire danger and fire season length, everywhere in southern Europe, as measured through the FWI System. The relative increase in mean seasonal fire danger ranges between 2 and $4 \%$ per decade in the Mediterranean regions of Europe, and it reaches $7 \%$ per decade in France, where the fire-prone area is currently limited to the south. The projected increase in severity of the fire season, as measured by the SSR, is even higher (3-7\% per decade in the Mediterranean area), and fire season lengths are projected to increase by 3-4 days per decade for the whole area of southern Europe. We note that these results mostly rely on three studies that differed in many aspects. One can claim that diversity in modelling options may bring robustness, but variations in definitions of fire danger metrics render comparisons between modelling results difficult, e.g. Bedia et al. vs Moriondo et al. in Appendix.

Future burnt areas have mostly been studied at continental scales, with the noticeable exception of the Iberian Peninsula, in which several regional- to national-scale studies estimated future burnt areas. Projected changes strongly depend on the models used to rate climate change impact, and in fact on the drivers that they incorporate. When only seasonal fire weather or the coincident drought is considered, burnt areas are projected to increase everywhere in southern Europe. This result is similar to those obtained from fire danger projections, but corresponding rates of increase are substantially higher (15 to $25 \%$ per decade for most areas, and much more for Spain). When the effects of fuel load/continuity are considered, through 
Table 2 Changes in fire metric (in $\%$ or days per decade)

\begin{tabular}{|c|c|c|c|c|c|}
\hline \multirow[b]{2}{*}{ Metric } & \multirow[b]{2}{*}{ Area } & \multicolumn{2}{|l|}{ Scenario A1B } & \multicolumn{2}{|c|}{ Scenario A2 or RCP8.5 } \\
\hline & & Mid-term & End of century & Mid-term & End of century \\
\hline \multirow[t]{8}{*}{ Mean seasonal FWI (\%) } & Southern Europe & $3.3^{2}$ & $4.0^{2}$ & & $2.1^{1}$ \\
\hline & Balkans & $2.6^{2}$ & $3.4^{2}$ & & $2.3^{1}$ \\
\hline & France $\left(<48^{\circ}\right.$ lat $)$ & & & & $2.6^{1}$ \\
\hline & France & $5.9^{2}, 5.2^{9}$ & $6.9^{2}, 6.1^{9}$ & $4.9^{9}$ & $7.2^{9}$ \\
\hline & Greece & $1.8^{2}$ & $1.9^{2}, 2.5^{20}$ & & $2.2^{1}$ \\
\hline & Italy & $3.2^{2}$ & $4.3^{2}, 1.8^{17}$ & & $2.3^{1}$ \\
\hline & Portugal & $2.7^{2}$ & $3.1^{2}$ & $9.1^{13}$ & $1.5^{1}$ \\
\hline & Spain & $3.1^{2}$ & $3.7^{2}$ & & $2.1^{1}$ \\
\hline \multirow{8}{*}{$\begin{array}{l}\text { Seasonal severity rating } \\
\text { SSR }(\%)\end{array}$} & Southern Europe & $5.0^{2}$ & $6.5^{2}$ & & $3.7^{3}$ \\
\hline & Balkans & $4.0^{2}$ & $5.5^{2}$ & & \\
\hline & France - MED & & & & $4.7^{3}$ \\
\hline & France & $10^{2}$ & $12^{2}$ & & \\
\hline & Greece & $3.0^{2}$ & $3.3^{2}$ & & $3.9^{3}$ \\
\hline & Italy & $5.1^{2}$ & $7.4^{2}$ & & $2.6^{3}$ \\
\hline & Portugal & $4.2^{2}$ & $5.0^{2}$ & & $4.9^{3}$ \\
\hline & Spain & $4.8^{2}$ & $6.3^{2}$ & & $4.3^{3}$ \\
\hline \multirow{8}{*}{$\begin{array}{l}\text { Length of fire season } \\
\text { (days) }\end{array}$} & Southern Europe & $3.4^{2}$ & $3.4^{2}$ & & $3.5^{1}$ \\
\hline & Balkans & $2.3^{2}$ & $2.5^{2}$ & & $3.4^{1}$ \\
\hline & France $\left(<48^{\circ}\right.$ lat $)$ & & & & $3.5^{1}$ \\
\hline & France & $5.2^{2}$ & $5.4^{2}$ & & \\
\hline & Greece & $3.1^{2}$ & $2.4^{2}$ & & $4.3^{1}$ \\
\hline & Italy & $2.6^{2}$ & $2.5^{2}$ & & $3.2^{1}$ \\
\hline & Portugal & $2.6^{2}$ & $2.3^{2}$ & & $3.3^{1}$ \\
\hline & Spain & $3.1^{2}$ & $3.0^{2}$ & & $3.8^{1}$ \\
\hline \multirow[t]{4}{*}{ Fire number $(\%)$} & Portugal & & & & $28^{12}$ \\
\hline & Spain & & & & $32^{14}$ \\
\hline & Regional (NE Spain) & $20^{23}$ & & & \\
\hline & Local (NE Spain) & & & & $20-23^{22}$ \\
\hline \multirow[t]{10}{*}{ Burnt area $(\%)$} & Europe & $3.7^{6}$ & $4.5^{6}$ & $10^{8}$ & $6.4^{7}, 10^{7}, 24(1.9)^{8}$ \\
\hline & Southern Europe & $1.4^{6}$ & $1.9^{6}$ & $14(9.7)^{4}, 9.0^{8}$ & $\begin{array}{l}16^{3}, 25(13)^{4} \\
3.7^{7},-7.6^{7} \\
20(-2.5)^{8}\end{array}$ \\
\hline & France-MED & & & & $14^{3}$ \\
\hline & Greece & & & & $18^{3}$ \\
\hline & Italy & & & & $4.8^{3}$ \\
\hline & Portugal & & & & $19^{3}, 48^{12}$ \\
\hline & Spain & & & & $93^{3}, 51^{14}$ \\
\hline & Iberian P. & $23(16)^{16}, 2.7^{6}$ & $3.6^{6}$ & & \\
\hline & Regional (NE Spain) & $-15^{23}$ & & & \\
\hline & Local (NE Spain) & & & & $9-96^{22}$ \\
\hline \multirow[t]{3}{*}{ Fire size $(\%)$} & Italy (+Corsica) & $0.7^{11}$ & & & \\
\hline & Regional (Greece) & & $6.9^{20}$ & & \\
\hline & Local (Greece) & $0.5^{21}$ & $2.3^{21}$ & & \\
\hline
\end{tabular}

Superscript numbers refer to projection study numbers defined in the Reference column of Table 1

vegetation dynamics in process-based models or climatic proxies (antecedent weather or drought conditions) in statistical approaches, burnt areas generally increase at much lower rate (not exceeding a few percent per decade) and can even decrease in the current most arid regions (e.g. south Iberian Peninsula).
Hence, large uncertainty exists about future trends in these regions. For the northern margins of the current Mediterranean area, fuel load/continuity is not likely to become a limiting factor and future increase in fire activity is expected there. Hence, the area at risk should expand to new fire-prone regions, 
such as the western and central France, the mountains surrounding the Mediterranean basin or central-eastern Europe.

Regarding fire number, we must expect an increase with fire danger, but very few results are available and do not allow to draw general conclusions, although increases consistently range between 20 and $30 \%$ per decade.

Even though local climatology is sensitive to elevation, this factor has been seldom accounted for until now, with a few exceptions. For example, Moriondo et al. (2006) have adapted the length of their fire season to location (hence to elevation), and aggregate their results over an altitudinal gradient.

\section{Limitations and uncertainties}

Reliability of fire danger or fire activity projections depends on the biases and uncertainties resulting from both climate projections and climate-fire models. The evaluation of climate projection uncertainty in climate impact studies is addressed in numerous past and on-going researches, and goes far beyond the scope of the present review (e.g. Foley 2010; Maraun 2016). In the context of fire projections, the main issues relate to the large biases observed in climate model predictions of temperatures and precipitations, and to the difficulty of detecting robust trends in fire metrics from inter-annual and decadal fluctuations. For climate-fire models, the main issues relate to their intrinsic performance in reproducing actual fire metrics but also to a number of fire factors of very different nature, which can be embedded in empirical climate-fire relationships. These factors include fuels, fire-vegetation feedbacks and human-related factors.

\subsection{Climate projections}

\subsubsection{Partition of uncertainty}

Uncertainty in climate projections arises from three distinct sources (e.g. Hawkins and Sutton 2009): internal or intrinsic variability of the climate system (natural fluctuations), model uncertainty (different models or even different runs of a given model, respond differently to the same radiative forcing), and scenario uncertainty (different emission scenarios lead to different radiative forcing). For mean annual global temperature, projections uncertainty is dominated by intrinsic climate variability and model uncertainty over the next few decades $(<$ 30 years), whereas emission scenarios led to the most variance at longer time scales (Hawkins and Sutton 2009). The most common approach for an assessment of climatic uncertainty is to generate a set of simulations (ensemble) from a set of models (multi-model) following contrasted scenarios or concentration pathways.

Several studies followed such a multi-model approach for fire danger or fire activity projections (studies 2, 4, 6, 7, 6, 16,
23). These studies consistently showed that uncertainties arising from climate models had important and significant impacts on wildfire projections. For instance, Sousa et al. (2015) provided ensemble means and inter-quartiles for burnt area trends in the Iberian Peninsula, and showed an uncertainty ranging from (roughly) \pm 20 to $\pm 60 \%$ in 2075 (inter-quartile over mean predicted burnt area), depending on the region of interest. Turco et al. (2018) also reported that the uncertainty in burnt area projections in southern Europe was dominated by the spread in climate models. Similar results were obtained for burnt areas projected with DVGMs (Migliavacca et al. 2013a). It is also interesting to note that climate model uncertainty is modulated by the fire metric under study (Lung et al. 2013; Bedia et al. 2014a). For instance, Bedia et al. (2014a) showed that threshold-dependent statistics (e.g. number of days above some FWI threshold) exhibited much higher model uncertainty than mean or 90th percentile FWI.

A number of reviewed studies have investigated the impact of scenario uncertainty on wildfire projections (studies 1, 3, 4, 7, 9, 14, 15, 18, 22). Early on, Moriondo et al. (2006) pointed out that increase in FWI by the end of the twenty-first century was much higher $(+23 \%)$ under the A2 than under the B2 scenario $(+16 \%)$ at the continental scale. These findings have since been largely confirmed by studies at regional (e.g. Loepfe et al. 2012) and continental scales (e.g. Amatulli et al. 2013).

The uncertainties due to both models and scenarios were only addressed in two of the projection studies reviewed in the present paper (studies 4,7 ). However, none of them provided a thorough assessment of uncertainty partition and its evolution over time. Turco et al. (2018) used two scenarios (RCP4.5 and RCP8.5), but selected periods to achieve a predefined warming target of $\left(+1.5,+2\right.$ or $\left.+3{ }^{\circ} \mathrm{C}\right)$ for burnt area simulations. Wu et al. (2015) provided the most detailed assessment of uncertainty partition over time (see Figure 4 in $\mathrm{Wu}$ et al. 2015), but did not partition the different uncertainty sources and combined climate scenarios (RCP2.6 and RCP8.5) with population scenarios. Thus, a thorough assessment of the respective sources of uncertainty is still missing in wildfire projections studies in southern Europe. In particular, a quantification of when and how fire danger or activity would excess the intrinsic variability of the climate system is still missing (see the notion of time of emergence, e.g. in Abatzoglou et al. 2019).

\subsubsection{Bias correction of climate model outputs}

Another source of uncertainty in fire projections arises from the bias correction of climate model outputs. To date, General Circulation Models (GCM) are run at too coarse spatial resolutions for a direct use of outputs to project wildfire danger or activity. Besides, global and regional climate models are generally strongly biased and these biases are likely to have 
significant impacts on the estimations of climate change impacts, as the climate-fire relationship is not linear. In simulations of 13 RCMs over Europe, Christensen et al. (2008) found systematic biases in monthly mean temperature and precipitations as shown by their evaluation against observational data. Turco et al. (2013a) also reported large biases in seasonal precipitations over Spain, as provided by the ENSEMBLES regional climate projections. Thus, climate model outputs are generally not directly used as input for climate-fire models without any form of bias corrections, especially when fire models are calibrated against observations. However, the implications of bias corrections methods are still a matter of debate in the climate research field, because they alter the consistency of spatiotemporal fields and the relations between variables, and they violate conservation principles (see Boberg and Christensen 2012; Ehret et al. 2012).

Among the projection studies reviewed in this paper, we observed several approaches regarding bias correction of climate outputs. Some studies used raw climate output, i.e. uncorrected for bias, for FWI projections (e.g. Moriondo et al. 2006; Bedia et al. 2014a), while others used one or several bias corrections methods (e.g. Amatulli et al. 2013; Migliavacca et al. 2013a; Sousa et al. 2015; Turco et al. 2018). Turco et al. (2018) evaluated the impact of bias correction on burnt area projection (by comparing the results obtained with and without bias corrections) and reported differences between those two sets of simulations.

Bias corrections in climate impact studies are commonly applied on temperature and precipitations, but other variables such as wind speed or air humidity have been little considered so far (Haddeland et al. 2012; Li et al. 2019). In the reviewed studies, only temperature and/or precipitations were corrected when bias was considered. Yet, both fire danger (here rated by the FWI) and fire activity are also sensitive to relative humidity and wind speed (e.g. Dowdy et al. 2010).

Furthermore, the choice of the bias correction method itself also has an impact on projections (Sousa et al. 2015). It should be noted that all bias correction algorithms used in the projection studies reviewed in this paper were applied to univariate time series and therefore neglected the dependence between different variables, which can be of importance for wildfire danger assessment (Cannon 2018). In this regard, the recent developments in multivariate bias corrections procedure can allow some refinements in wildfire projections (Vrac and Friederichs 2015; Cannon 2018).

\subsection{Climate-fire models}

\subsubsection{Fire Weather Index}

The relevance of using the FWI System to project the climate impacts on future fires depends on its ability to represent both the fuel moisture dynamics (FFMC, DMC and DC) and the effects of fuel moisture and atmospheric conditions on fire behaviour and activity (ISI, BUI and final FWI codes), in the specific context of Mediterranean weather and fuel conditions.

The FFMC has been designed to represent the moisture of dead fine fuels (litter, elevated dead material, cured grass), which, with wind speed, determines fire-spread rate in a given fuel complex. Aguado et al. (2007) found that the FFMC correlated fairly well $\left(r^{2} \sim 0.5\right)$ with the fine fuel moisture of litter. Resco de Dios et al. (2015) confirmed such correlation but also reported significant bias and dispersion errors in FFMC, as well as in other dryness indices tested in the study.

Shrubs are widespread Mediterranean fuels and the moisture of their foliage (live fuel moisture content, live FMC) can be an important fire driver (Yebra et al. 2013). Recent findings have confirmed the somewhat controversial effect of live FMC on fire spread and activity, motivating further attention to its prediction (Rossa and Fernandes 2018; Pimont et al. 2019). Several studies showed that the moisture content of some Mediterranean shrub species was correlated with the DC (Castro et al. 2003; Ceccato et al. 2003; Pellizzaro et al. 2007; Viegas et al. 2001), but the strength of the correlations was moderate, especially when the moisture dataset included a variety of sites and species (Ruffault et al. 2018). A hypothesis that to date has been seldom accounted for is that the response of plants to drought varies among species type and biomes (McDowell et al. 2008; Vicente-Serrano et al. 2013; MartinStPaul et al. 2017). Indeed, when applying the FWI System, the drought influence on plants is implicitly assessed from components (DC, DMC, FFMC) originally developed for dead fuels. These sub-components do not account for specific responses, and the same issue holds for other drought indices, including the SPEI used by Turco et al. (2018). Plants exhibit various strategies to resist drought (some avoid the desiccation of their living tissues whereas others allow some dehydration during drought), and such strategies could vary according to their habitat aridity (Volaire 2018).

Fire intensity is a fundamental fire behaviour variable as it measures the energy release rate of a spreading fire front and largely determines fire suppression difficulty and some fire effects (Van Wagner 1987). As mentioned by many projection studies among those reported in Sect. 2, the FWI has been scaled with fire intensity, as it was designed to reflect variations in Byram's fire intensity. This scaling was based on a set of 22 experimental fires in pine stands in Canada (Van Wagner 1974). However, the understanding of FWI-fire intensity relationships is quite limited, especially for European vegetation types. Palheiro et al. (2006) related the intensity (up to $100 \mathrm{MW} \mathrm{m}^{-1}$ ) of experimental fires and wildfires in Pinus pinaster stands with the FWI or the ISI in combination with the BUI and succeeded in explaining 68-80\% of the observed variation, depending on modelling option. Surface and forest floor fuel consumptions, which impact fire intensity, were 
found to be correlated with the DMC and BUI codes in Mediterranean pine stands, although the response ceases beyond moderate dryness levels (Palheiro et al. 2006; Fernandes and Loureiro 2013). However, similar attempts in shrublands, which are widespread in southern Europe, have been largely unsuccessful. This highlights the difficulty in extending the FWI System beyond its conditions of development and the need for FWI modifications, including in the representation of fuel moisture and fire behaviour (Anderson 2009). For instance, Chelli et al. (2015) have calibrated the FFMC and the DMC of the FWI System to improve the prediction of measured fuel moisture content in two regions of Greece and Portugal.

Fire danger being not an observable variable, fire activity is often more relevant to decision makers and land fire managers than a fire danger index, even scaled with fire intensity. Yet, there are clear evidences in Europe that fire danger as rated by the FWI is indicative of fire activity. Large fires in southern Europe (> $500 \mathrm{ha}$ ) are associated with high values of FWI codes (Camia and Amatulli 2009). In Sardinia and Corsica, Ager et al. (2014) found that 'an increase in the FWI from 30 to 60 produced on average an approximate eightfold increase in the odds of a large fire'. In Portugal, the increasingly high FWI relates to the development of increasingly larger fires (Fernandes et al. 2016a), with a steeper response for fires $>$ 2500 ha (Fernandes et al. 2016b). The FWI has successfully been used to define fire danger classes based on wildfire duration as observed by satellite sensors in southern Europe (DaCamara et al. 2014). Finally, the FWI codes may well correlate with observed burnt areas in Europe (Sect. 2; Amatulli et al. 2013; Bedia et al. 2014a). However, Carvalho et al. (2010) and Amatulli et al. (2013) both emphasized that FWI-based projections can also lead to unrealistic burnt areas, because the DC and the DMC are not bounded by an upper value and thus can reach extreme values under hotter or drier future climate.

\subsubsection{Significance of FWI-based metrics}

Studies projecting fire danger have often averaged the FWI across the territory of interest or over the fire season. According to the description of the FWI System, the FWI is considered 'not suitable for averaging and should be used as its single value daily' (Van Wagner 1987). As we already noticed, when an average fire danger over a season is desired, it is recommended to average the DSR, which scales with a 1.77 power of the FWI, resulting in the SSR. Only a few studies have used the SSR. According to Van Wagner (1987), the DSR reflects the fact that fire control difficulty rises sharply (not linearly) with the FWI. Moreover, Flannigan et al. (2013) have reminded that the DSR was originally created to compensate for the exponential increase in area burnt with fire diameter. This implicitly means that burnt area should scale exponentially with the FWI, suggesting that it should be more sensitive to climate change than the FWI. Hence, we suggest that although means and percentiles of FWI have a statistical meaning (central tendency and dispersion of the distribution of values in a territory or over a season), they do not have a physical or an operational meaning (such as fire control difficulty in a territory or over a season). On the contrary, fire number and burnt areas are well-defined metrics with a physical and an operational meaning, and can be spatially or temporally integrated.

Fixed thresholds values of daily FWI have been used to define more or less high fire-danger days, and project how their number will evolve under climate change. It would be attractive to consider these thresholds as standards, but we rather suggest that they have limitations. Moriondo et al. (2006) referred to a report by Hanson and Palutikof (2005) to justify the use of 15 and 45 as threshold values for elevated $(>15)$ and extreme fire danger $(>45)$, and then later studies have used these values. This analysis was in fact published later on in Good et al. (2008): the FWI thresholds of 15 and 45 for elevated and extreme fire danger respectively, were obtained from an analysis of fire density against FWI in the vicinity of 7 meteorological stations in Greece and Italy. First, these thresholds were visually estimated and thus are somewhat arbitrary. Second, other threshold values might have been found if data were collected at other locations, and indeed, Karali et al. (2014) found that thresholds corresponded to a given fire density highly dependent on the region of Greece considered. Hence, we rather consider them as orders of magnitude.

Moreover, the number of days above thresholds is likely very sensitive to the method used for the computation of the FWI (see Appendix), as well as to the bias correction that might be applied to climate simulations (see Sect. 4.1). In this way, the use of fixed thresholds was found to lead to important uncertainties as compared with other more stable metrics such as FWI percentiles (Bedia et al. 2014a), which moreover are location-dependent. Although the FWI computation is welldefined, several methods have been proposed for its computation from climate simulation datasets, because they often only include daily variables, while the FWI should be computed from 12:00 (LST) values of temperature, relative humidity and wind speed. This strongly impacts the FWI values (Herrera et al. 2013). Hence, several proxies have been used to estimate the FWI from daily variables. These aspects, in addition to bias correction mentioned above, make it difficult to define a stable reference level for the FWI among climate simulations.

In most of the projection studies examined in this review, fire season was defined as a fixed number of days or months. The selection was either based on the calendar summer months or by setting a threshold value of time-averaged FWI (e.g. 2-week average FWI > 15 in Moriondo et al. 
2006). However, there are several issues associated with this approach. Fire season definition had a strong impact on the reported metrics (see Appendix) which impeded a fair comparison between projection studies. Moreover, the selection of this period generally applies to the whole area considered by the study, while the fire season likely depends on local characteristics, such as elevation. Finally, climate change may induce significant fire activity out of the current fire season in the future that cannot be captured with a fixed fire season length. A variable fire season length therefore appears as a better solution but this again raises the issue of defining when fire danger becomes significant. In the reviewed projection studies, a single threshold (as suggested by Moriondo et al. 2006) has been used, while temperature-based thresholds have been used in other continents or globally. One should also note that in case the fire season expands in the future, a mean FWI or SSR could be biased by the addition of relatively low danger days. This issue has been first raised by Flannigan et al. (2013) who introduced the Cumulative Severity Rating (CSR) as the sum of DSR values over the fire season (rather than its mean) to rate the seasonal fire danger. The CSR can be computed in the future for both the historical and future fire seasons and allows to separate the contribution of fire activity increase during the historical fire season (due to increased fire intensity) from the contribution of fire season lengthening (more days with significant fire danger) to the total change in fire activity. We suggest the CSR or similar cumulative rating as the best option for future studies.

\subsubsection{Statistical-correlative fire models}

Reviewed projection studies revealed spatial and temporal variations in the climate-fire relationship. In this respect, explained variances of the burnt area models (reported in Sect. 2) ranged between 10 and $90 \%$ according to the eco-region or country and to the modelling approach, the sensitivity of burnt area to the FWI or to SPEI-based variables changed across regions (Bedia et al. 2014a; Turco et al. 2018), and it is likely non-stationary (see comments on Turco et al. 2018 in Appendix). Such variations have already been observed elsewhere (e.g. Littell et al. 2009; Higuera et al. 2015; Keeley and Syphard 2016) or in other European studies (e.g. Bedia et al. 2014b; Ruffault and Mouillot 2015; Fernandes 2019), raising the question of whether current empirical relations are applicable in the future. Fuel variations and climate-fire-vegetation feedbacks (e.g. Brotons and Duane 2019), as well as humanrelated factors (e.g. Ruffault and Mouillot 2015) are likely to shape these relations (see Sects. 4.3 and 4.4).

The quality of fire datasets used to derive the statisticalcorrelative models is rarely documented or described, although inaccuracies have been reported and contribute to uncertainty in burnt area predictions (Pereira et al. 2011; Turco et al. 2013c; Ruffault and Mouillot 2015). Such uncertainty can reduce the strength of the estimated climate-fire relationship.

In the reviewed studies, most climate data were daily data, but the weather statistics (or fire danger or drought indices) used as predictors in the burnt area models were monthly or seasonal variables. In some regions or at country level, these temporally averaged variables can explain a large part of the interannual burnt area variability, as illustrated above. However, their temporal resolution is likely too low to capture the extreme fire events triggered by extreme fire weather consecutive days that much contribute to burnt areas (Hernandez et al. 2015), further questioning the reliability of the statisticalcorrelative models.

\subsubsection{Spatially explicit fire spread models}

Simulations of spatially explicit fire spread models could help overcome some of the limitations of statistical climatefire models often used for projections of climate change impact. Indeed, these simulations permit to account for explicit effects of climate/weather variables on fire behaviour processes, through the fire spread equations, and the influences of other fire drivers such as fuels or human-related factors (see Sects. 4.3 and 4.4) that can explain spatial or temporal variations in the climate-fire relationship. In addition, a variety of local fire behaviour outputs, instead of a single indicator, can be used to characterize fires. However, this approach requires additional estimation and modelling components, or strong assumptions, since fuel attributes (type, moisture content) as well as ignition density patterns and fire duration must be specified or predicted. For example, in Lozano et al. (2017), it was assumed that ignition density patterns in the future do not depart from the historical period; all fire simulations (current and future) were carried out for exactly $10 \mathrm{~h}$ after ignition, land cover was represented by a single fuel type, selected among only three fuel models for the whole country. The outcomes of the study might be sensitive to these critical, but currently necessary, assumptions. Similarly, Kalabokidis et al. (2015) and Mitsopoulos et al. (2015) ran fire simulations under constant historical ignition density and constant fire duration. Hence, in these three projection studies, the impact of climate change was accounted for through changes in fire spread driven by the changes in the distribution of wind speeds (which are generally minor) and in fuel moisture levels, whereas the effects of climate change (in terms of weather or fuel moisture) on both ignition and extinction (or duration) of fires were ignored. Clearly, these studies provide insights on future climateinduced changes in fire behaviour variables and mean fire size conditional to specified ignition, duration and also fuel types (i.e. current fuel types are used), but the projections of fire activity are probably still incomplete. 


\subsubsection{DGVM-fire models}

Thorough and systematic evaluation of DGVM-fire models is the subject of ongoing research projects (Rabin et al. 2017). Here, we successively examine the performance in fuel moisture and burnt area predictions of the models used in the reviewed studies, according to previous evaluation of the fuel moisture models and to data reported in the reviewed studies.

SIMFIRE and SPITFIRE in Wu et al. (2015) use functions of the Nesterov index to represent the fuel moisture effect on fire, as well as the fuel moisture itself in the case of SPITFIRE. The Nesterov index has shown poor correlations with litter or grass fuel moisture content and in fact the poorest correlation among the five metrics tested by Ganatsas et al. (2011) in Mediterranean conditions. This index was also the worse predictor of live fuel moisture content among the six categories of indices tested by Ruffault et al. (2018). In addition, evaluations of Nesterov index against fire danger have also shown the lowest correlations with fire density in Germany (Holsten et al. 2013), with Pearson correlation of 0.5 in order of magnitude, to be compared with $0.6-0.7$ obtained with the FWI (highest correlation in this study). Hence, using functions of the Nesterov index might not be the best option to represent fuel moisture dynamics or moisture effect on fire.

The fire models used with the CARAIB DGVM in Dury et al. (2011) and with the CLM-AB DGVM in Migliavacca et al. (2013a) use the DGVM prediction of soil moisture as a surrogate for fuel moisture. Actual (i.e. measured) soil moisture content has been shown to be a good explanatory variable of litter or grass moisture content, better than weather variables or drought index in the case of litter (Ganatsas et al. 2011), which suggests that a modelling of litter or grass fuel moisture derived from soil moisture is a relevant option. More recently, Ruffault et al. (2018) showed that soil moisture, as predicted by a water balance model (analogue to hydrological models in CARAIB and CLM-AB), was also the best predictor of live fuel moisture content among the six categories of indices tested. Those findings suggest that using the hydrological module of a DGVM for representing live fuel moisture seems to be a relevant option, better than any drought index. Moreover, the hydrological module of CARAIB captured the spatial patterns of water runoff across Europe, although their magnitude was systematically underestimated (Dury et al. 2011).

The maps shown by Wu et al. (2015, Fig. 1) reveal large biases in burnt area predictions. With respect to fire databases, burnt areas were overestimated for parts of Spain, half eastern France, some regions of central-eastern Europe and the coastal margins of Turkey, especially with LPJmL-SPITFIRE, which for example predicts unrealistic fractional burnt areas per year in eastern France. In contrast, burnt areas are underestimated in the north-western part of the Iberian Peninsula, which exhibits the highest fire activity in southern Europe. According to Figure 2 in $\mathrm{Wu}$ et al. (2015), the two models do not seem to capture interannual variations in burnt areas in the Mediterranean basin, but temporal and spatial correlations were not reported. We already mentioned the large overestimation of burnt areas with the model used by Migliavacca et al. (2013a). This model results from an improvement of the original CLM-AB model through better parameterization of fire ignition/suppression (Migliavacca et al. 2013b): the seasonal variations and the summer peak in fire activity were reproduced well by the improved model, but the interannual variations (i.e. deseasonalized time-series) still exhibited modest $(\sim 0.4)$ or even low ( 0.17 for Portugal) correlations. In fact, time-series of monthly burnt areas over 1991-2009 show similar modelled peak fire activity every year, whereas the interannual variation of the actual peak is large. Hence, definitely, the model does not capture interannual variability, which questions its ability to simulate the climate impact on burnt areas.

Burnt areas predicted by Dury et al. (2011) with the CARAIB-CTEM model underestimated the observed data, but in this study the objective was to simulate the potential fire regime without people, hence human-related factors were not considered in the simulation. The model reproduced interannual variability of burnt areas at European scale quite well (correlation 0.76).

\subsection{Influence of fuels and fire-vegetation feedbacks}

Important shifts in the potential vegetation distribution are projected in Europe owing to changes in climate conditions (e.g. Hickler et al. 2012; Costa et al. 2015), although trends are still uncertain (e.g. Cheaib et al. 2012; Lindner et al. 2014). These shifts could alter fuels, and changes in fire regimes could accelerate such shifts. So far, spatial and temporal fuel variations and fire-vegetation feedbacks have largely been ignored in reviewed projection studies. Yet, fuel load/continuity has been suggested to shape the climate-fire relationships in the most arid regions of Europe (e.g. Pausas and Paula 2012; Loepfe et al. 2014) and interannual variations in weather conditions prior to the fire season (from a few months to a couple of years before) might also affect burnt areas through fuel accumulation (e.g. Turco et al. 2013b, 2014; Koutsias et al. 2013). Only projection studies based on DGVM-fire models have explicitly taken into account fuel dynamics as driven by climate and fire feedbacks, but we already reported that the agreement of these models with burnt area data was relatively poor and that their predictions can strongly diverge depending on modelling assumption (e.g. $\mathrm{CO}_{2}$ fertilization effect). Moreover, an important issue when developing or evaluating models that attempt to predict fuel load dynamics and patterns is that to date only surrogates for fuel load are available at large scales (Knorr et al. 2012). 


\subsection{Influence of human-related factors}

In most regions of the world, humans influence fire activity in many ways including ignitions, suppression activity or fuel modifications (Bowman et al. 2011). As a result, population density has been observed to influence fire ignitions, fire size and burnt areas (e.g. Knorr et al. 2013; Hantson et al. 2015). In Europe, fire ignitions are mostly anthropogenic (Ganteaume et al. 2013). Land use alters landscapes, decreasing or increasing forest continuity and inducing variations in vegetation cover and fuel load that eventually affect fire activity (Moreira et al. 2011; Pausas and Fernández-Muñoz 2012; Martínez-Fernández et al. 2013; Fernandes et al. 2014). Fire prevention and suppression have also drastically affected fire regimes, decreasing burnt areas in the recent decades, as suggested by a number of studies (Turco et al. 2013c; Brotons et al. 2013; Moreno et al. 2014; Salis et al. 2014; Ruffault and Mouillot 2015; Turco et al. 2016). It must be noticed however that fire suppression does not seem to impact the incidence of large fires (San-Miguel-Ayanz et al. 2013; Evin et al. 2018).

\section{Summary and future directions}

\subsection{Projected trends}

Despite the heterogeneity in methods and results of reviewed studies, all projection studies based on the FWI System agree on a generalized future increase in fire danger and fire season length in southern Europe. The relative increase in mean seasonal fire danger up to the end of the century under the pessimistic climate change scenarios ranges between 2 and $4 \%$ per decade in the Mediterranean regions of Europe, and it reaches $7 \%$ per decade in France. When fuel load/continuity dynamics are ignored, burnt areas are projected to increase everywhere in southern Europe, just as the potential fire danger does but with substantially higher rates of increase (15 to $25 \%$ per decade for most areas, and much more for Spain). Large uncertainties remain when considering fuel dynamics. Area at risk should expand to new fire-prone regions, such as western and central France, the mountains surrounding the Mediterranean basin or central-eastern Europe, where fuel load is not expected to be a limiting factor. In the warmest and driest fire-prone regions (e.g. central and southern Iberian Peninsula), fuel availability is or would become the main limiting factor of fire activity.

\subsection{Need for projection standards and meaningful fire metrics}

A lack of standards has been identified in the definition of some fire metrics, in their computation, and in the way the results are reported, which was a major obstacle to compare studies' results. The reviewed studies differed by the climatefire model used. It is of high interest to get comparable results from different models in order to estimate model uncertainties and confidence intervals, similarly to ensemble climate modelling. However, reviewed projections studies were found to be highly heterogeneous beyond the diversity of fire models, making comparisons difficult and precluding replication. We suggest that the scientific fire community works on deriving common definitions and standards of the fire danger metrics to be reported in future studies. This must include a sound evaluation of the fire danger concept and how to rate this danger. In this respect, we suggest that fire activity variables such as fire density (number of fires per time and per area) and fractional burnt area (burnt area per time and per area) are the key operational data that need to be related with fire danger metrics. Fire number and burnt areas are welldefined metrics that have a physical and an operational meaning, and they can be spatially or temporally aggregated, hence they do not have the same drawbacks as fire danger metrics. Another promising area of work is the standardization of the rate of change in fire metrics with respect to projected change in climate (basically, rate of change in temperature and precipitation). Indeed, climatic projections differ among scenarios, climate models and associated methods and data such as bias correction or climate reanalysis, leading to important variations in projected climatic variables. However, the current status and the future trends of the climatology are rarely reported in projection studies. Reporting such quantities in addition to fire danger metrics would ease the comparisons among studies. Finally, performing error estimation and uncertainty analysis in projection studies should also become a standard. Reviewed projections in Europe lacked error estimation and at best provided an incomplete analysis of the uncertainties associated with climate projections, while the uncertainty associated with climate-fire models is ignored. We acknowledge that the state of knowledge, data and resources can hinder uncertainty analysis, but this is a fundamental aspect that questions the reliability of depicted trends and requires further research.

\subsection{Fuel processes}

Fuel load/continuity has been reported to significantly alter the climate-fire relationship in Europe, and a specific response to live fuel dryness could also play a role. These fuel aspects should hence be incorporated in projections to avoid spatial or temporal bias arising from spatial or temporal fuel variations. This involves important research efforts for understanding fuel processes and predicting fuel load and fuel moisture. Indeed, commonly used drought indices can be poorly correlated with both dead and live fuel moisture content. For dead fuels, other options have been developed, including tractable methods based on vapour pressure deficit. For live fuels, there 
is a need for more fundamental research to understand the physiological processes driven by water potential in plant and soil that ultimately govern water content dynamics. Fuel moisture prediction involves not only the prediction of water content dynamics but also the dry matter content of fuel elements (i.e. mass per area), hence both the carbon and water cycles in plants. Considering fuel load dynamics involves the processes of vegetation dynamics and carbon fluxes, which in turn will be influenced by both climate warming and $\mathrm{CO}_{2}$ increases. Reviewed studies based on DGVM-fire models suggested that $\mathrm{CO}_{2}$ fertilization itself could play a role as important as climate warming on fuel dynamics. Thus, the process-based modelling of fuels in relation to climate appears as a challenging pathway, involving plant functioning and biogeochemical cycles, to project climate change impacts on fire activity or behaviour. To date, the complex fuel processes have generally been ignored in simple climate-fire models such as fire danger indices or statistical models, which likely weakens the accuracy of their predictions.

\subsection{Vegetation shifts}

The long-term evolution of fuels under future climate is another large source of uncertainty, as it involves both change in ecological niches of plant species and human impacts in terms of forestry and wildland management. DGVM-fire models aim at accounting for changes in fuel structure and fire severity associated with vegetation transitions, in addition to fuel load dynamics. A number of DGVM-fire models have been developed to date, including either empirical or process-based fire modules, and the community has recently initiated a project of global fire models inter-comparison (Hantson et al. 2016; Rabin et al. 2017). More generally, evaluation and further developments of these models and of their fire and vegetation components, at both global and regional scales with different degrees of refinement, is certainly a good option to gain new understanding and better prediction capabilities of fire regimes. Indeed, in the reviewed studies, it was found that the agreement of these models with observed data is relatively poor and that their predictions can strongly diverge.

\subsection{Anthropogenic processes}

Most projection studies do not account for the impact of fire management and socio-economic drivers on fire activity. Burnt areas declined since about the 1990s in most fireprone regions of Europe, which is largely explained by fire control policies. It is of great importance to assess how the fire danger increase might affect the success of these policies, especially because fire suppression does not seem to impact the incidence of large fires. In that respect, the capacity of fire suppression policies to contain fires that occur under extreme fire weather and are likely to become extreme fire events, is of central importance. There is also critical need to assess the impact of continued land abandonment that may foster increasingly large fires in nonfuel-limited environments. More generally, long-term variations in human-driving fire influences need to be better understood. Then, projections could be carried out under various policy scenarios to inform the decision-making process.

Acknowledgements Acknowledgements are expressed to the French Ministry of Agriculture, which funded the $\mathrm{PhD}$ researches of one of the co-authors.

Funding information This paper has been prepared under the framework of the project MedWildFireLab ('Global Change Impacts on Wildland Fire Behaviour and Uses in Mediterranean Forest Ecosystems, towards a «wall less» Mediterranean Wildland Fire Laboratory') funded by ERANET FORESTERRA, and project UID/AGR/04033/2019 funded by the FCT (Fundação para a Ciência e a Tecnologia).

Data availability Data sharing not applicable to this article as no datasets were generated or analysed during the current study.

\section{Compliance with ethical standards}

Conflict of interest The authors declare that they have no conflicts of interest.

\section{Appendix}

To complete Table 2, we used the quantitative results of the projection studies reported in the text or tables, or shown in figures. Results were classified according to the nature of the fire metric and the geographic area (rows of Table 2), the emission scenarios (A1B and A2/RCP8.5) and the timehorizon considered (mid-century and end of century) (columns of Table 2). Too few studies dealing with other scenarios or other time-horizons have been carried out to be included in this table. The first part of Table 2 reports fire danger metrics based on the FWI System and the second part reports fire activity metrics derived from statistical-correlative fire models, spatially explicit fire spread models and DGVM-fire models. For the sake of comparison, we calculated, for each study, the relative rates of change of the fire metrics per decade up to the time horizon considered. For fire season length, we reported changes in days per decade. Normalizing by the number of decades reduces the differences resulting from the different definitions of the reference and future periods between studies. Finally, we felt it would also be relevant for the purpose of our review to report climate trends expressed as change by decade (e.g. Celsius degrees per decade), but this data was almost never available in the reviewed studies. Some studies were not included in Table 2 because no quantitative results were provided (e.g. only maps). 
In the following, we provide detailed comments on the results of Table 2, with the aim to understand differences or similarities between studies.

\section{Fire danger}

For the Balkans, Italy, Portugal and Spain, the increases in mean FWI reported by Moriondo et al. (2006) by the end of the century are lower than those reported by Bedia et al. (2014a), though they considered a less severe scenario (A1B instead of A2). For France and Greece, they are slightly higher. When comparing the two studies, several important differences must be kept in mind. First, as pointed out by Bedia et al., Moriondo et al. used only one RCM exhibiting a strong positive bias in FWI with respect to a climate reanalysis of the historical period in several regions of southern Europe and the lowest spatial correlation among the six models that Bedia et al. selected. This model was thus discarded in the Bedia et al. study. Note that Moriondo et al. did not report whether the model bias was corrected. Second, as shown by Bedia et al. again, the proxy used by Moriondo et al. to compute the daily FWI (defined at noon) from daily meteorological variables resulted in lower FWI values compared with the reference values derived from hourly (noon) values, hence a negative bias that could compensate for the positive bias caused by the climate model. In contrast, Bedia et al. used a different proxy providing FWI values closer to the reference values. Third, the mean FWI was computed for a fixed period of the year (June to September, 120 days) in Bedia et al., while Moriondo et al. computed the mean FWI on a locally variable fire season length, ranging between 55 days and 127 days in the historical period according to the country. Only Portugal (127 days) and Spain (110 days) in Moriondo et al. study had a mean fire season length close to the 120 days used by Bedia et al. to compute the mean FWI; in other countries, fire season lengths were lower. Keeping in mind that this mean number hides large local disparities following elevation in each country, on the historical period, this difference between the two studies should nevertheless increase mean FWI values in Moriondo et al. as compared with Bedia et al., since the period is more or less centred on summer. Despite the above differences, it is worth noting that except for the particular case of France for which geographical areas of the two studies are also different, both studies show similar historical values of the mean FWI, ranging between 28 and 33 in Moriondo et al. and between 23 and 35 in Bedia et al. This suggests that compensations effectively occurred among the sources of variation in mean FWI reported above. On the future period, the fire season length increased for all countries according to Moriondo et al., exceeding the 120 days used by Bedia et al. for Greece, Portugal and Spain.

Bedia et al. (2014a) also computed fire season lengths using the same FWI threshold value (15) as Moriondo et al.
(2006). The fire season lengths computed by Bedia et al. in the historical period (not shown) however are roughly 2 - to 3 -fold the values computed by Moriondo et al. It is attracting to explain this strong difference by the negative bias caused by the Moriondo et al. proxy for noon FWI estimation; however, some compensation from the positive bias due to the climate model should also be expected. In France, the current fire season length was 108 days in Bedia et al. (2014a), whereas it was only 55 days in Moriondo et al. (for more southern latitudes, $<48^{\circ}$ ). We consider that the value by Bedia et al. (2014a) is largely overestimated since the operational fire season lasts typically 2 months and half in the most fire-prone region of France (South-East). This questions the use of either the threshold FWI value of 15 or the magnitude of FWI values in Bedia et al. Both studies predict increases of fire season length of about 3 days per decade up to the end of the century. Moriondo et al. predicted slightly higher increases than Bedia et al. in Mediterranean countries (Balkans, Greece, Italy, Spain and Portugal), but lower in France (where we remind again that the geographical area was different in the two studies).

Both historical and future SSR values predicted by Amatulli et al. (2013) under the A2 scenario are lower than those reported by Bedia et al. (2014a) under the A1B scenario, especially for France and Italy. This is consistent with the fact that SSR was computed from May to November in Amatulli et al., while Bedia et al. used the June to September period. The absolute increases in SSR predicted by Bedia et al. (roughly 0.6 per decade) are also much higher than those predicted by Amatulli et al. (roughly 0.2 per decade), which also makes sense because of the difference in fire season lengths.

Other studies that report mean FWI are from Chatry et al. (2010) in France, Arca et al. (2012) in Italy, Carvalho et al. (2011) in Portugal, and Kalabokidis et al. (2015) in a region of Greece.

In an exploratory study of fire danger evolution in France, Chatry et al. reported annual means of FWI (and number of days above several FWI thresholds). They found an increase of the annual mean FWI of $6.9 \%$ per decade for the whole area of France in scenario A2, whereas Moriondo et al. (2006) found an increase of the seasonal FWI of $2.6 \%$ for the southern half of France (latitude $<48^{\circ}$ ). This great difference could be partly explained by the respective geographic areas of the two studies, but also by the respective periods considered for the computation of the mean FWI (whole year versus a variable fire season). In contrast, relative increases reported by Chatry et al. under scenario A1B are similar for both horizons to those reported by Bedia et al. (2014a). However, Chatry et al. found annual mean FWI values of 4.4 and 7.4, while Bedia et al. found mean summer (June to September) FWI values of 12 and 20, for the historical and future (end of century) periods respectively. 
Arca et al. (2012) reported present and future mean FWI for the four seasons of the year and found an increase of the mean summer (July to September) FWI of $1.8 \%$ per decade for Italy under the A1B scenario, while Bedia et al. (2014a) found an increase of $4.3 \%$ per decade for a similar season (June to September). The mean FWI values in Arca et al. are 26 and 31 , while they are 23 and 33 in Bedia et al., respectively for the historical and future periods. Note that Arca et al. found the same FWI increase $(+5)$ in spring and in summer, while Bedia et al. found an increase of 10 for the June to September period, hence the difference is clearly not due to the definition of the season. Another difference between the two studies is that Arca et al. used only one RCM with no bias correction.

Carvalho et al. (2011) found a mean relative FWI increase of $9.1 \%$ per decade under A2 scenario up to mid-century in Portugal, while Bedia et al. (2014a) found a $2.7 \%$ per decade increase under A1B scenario. The mean FWI values in Carvalho et al. are 10 and 15, while they are 32 and 38 in Bedia et al., respectively, for the historical and future periods. Carvalho et al. computed the mean FWI from February to October, which is likely to explain the important difference between the FWI levels of the two studies, but the absolute increases are similar. Moreover, when using Carvalho et al. data to compute change in mean FWI for the upper classes of FWI (e.g. FWI > 15), hence values likely more concentrated in the summer period, the relative increase drops to $2.6 \%$ per decade, close to the prediction of Bedia et al. Therefore, it seems that the predictions by Bedia et al. and Carvalho et al. are compatible, contrary to what the data reported in Table 2 suggest at first glance.

When using the monthly FWI values reported by Kalabokidis et al. (2015) for a region of Greece, the increase in seasonal (June to September) FWI is $2.5 \%$ per decade up to the end of century under the A1B scenario, which is slightly higher than the increase of $1.9 \%$ per decade by Bedia et al. (2014a) for the whole Greece. The mean FWI values in Kalabokidis et al. are 27 and 34, while they are 35 and 41 in Bedia et al., respectively for the historical and future periods; hence, the FWI levels strongly differ between the two studies, but the increases are similar.

One could argue that it would be more valuable in our review to compare statistics such as number of days above threshold values instead of means (or quantiles) of the FWI. Some studies report such statistics, but using different threshold values, and the pertinence of these thresholds might be location-dependent. Hence, again, comparisons are complicated by different choices and we were not able to show comparisons of such statistics.

\section{Fire activity}

Among projection studies at continental scale, only the Amatulli et al. (2013) study also reports the results down to national scale. Many reports and scientific papers refer to the Amatulli et al. study to mention expected changes in future burnt areas in Europe. Amatulli et al. built regression models of burnt area on components of the FWI at a monthly time scale for the Mediterranean countries of the European Union. Projected relative burnt area increases were $16 \%$ per decade under A2 scenarios for Mediterranean Europe (or 2.4-fold increase by the end of century), ranging between $5 \%$ (Italy) and $93 \%$ (Spain) per decade according to the different countries.

Turco et al. (2018) projected burnt area in Mediterranean Europe, assuming that seasonal fire activity is driven by the coincident seasonal drought, as supported by recent work analysing historical burnt areas (Turco et al. 2017). They found that the sensitivity of burnt area to drought conditions, as measured by monthly statistics based on the SPEI, was lower in sub-regions of southern Europe exhibiting the highest temperatures. For this reason, they built both stationary (sensitivity to SPEI is constant in time) and non-stationary (sensitivity to SPEI decreases with time-averaged temperature, hence decreases in the future) models for burnt area by ecozones of Mediterranean Europe. The lower sensitivity in the hottest region was suggested to reflect some human and vegetation adjustment/adaptation. The stationary model predicted a $25 \%$ burnt area increase per decade at the scale of southern Europe, higher than the one reported by Amatulli et al. (2013) (16\% per decade). Note that Amatulli et al. used climate data from one GCM/RCM, whereas Turco et al. (2018) used 9 simulations from several GCM/RCM couplings. The non-stationary model logically resulted in lower increases in burnt area (13\% per decade).

At continental scale, the two studies by Migliavacca et al. (2013a) and Wu et al. (2015), which both use DGVM-fire models, exhibit much lower increases than the studies by Amatulli et al. (2013) and Turco et al. (2018), which both use statistical models. DGVM-fire models incorporate vegetation and fuel dynamics that can lessen the impacts of fire weather increase on fire activity when fuel availability becomes critical, but such low increases could also have other reasons.

Migliavacca et al. (2013a) found very low relative increases in future burnt areas (e.g. 1.9\% per decade for southern Europe), which in fact is likely due to their DGVM-fire model largely overestimating the historical burnt areas: for instance, the predicted historical (1990-2010) burnt areas were, e.g. 800,000 ha for the Iberian peninsula, whereas the actual historical mean burnt area is 130,000 ha according to the European Forest Fire Information System. The absolute increase by the end of the century predicted by the model was 130,000 ha for the Iberian Peninsula; hence, a two-fold increase relative to the actual, historical burnt area in the future period. Such large discrepancy between modelled and observed historical burnt areas is also visible in the data by 
Migliavacca et al. (2013a) at the whole European scale (all these data are shown in a Supplementary File). This strongly questions the reliability of the low relative increases that the authors claim to be more conservative estimates than previous dramatic increases of say 3- to 5-fold obtained without considering fuel dynamics (Amatulli et al. 2013).

Wu et al. (2015) found low increase in burnt area (3.7\% per decade) with LPJ-GUESS-SIMFIRE, as compared with Amatulli et al. (2013), or even decrease in burnt area ($7.7 \%$ per decade) with LPJ-mL-SPITFIRE, for the Mediterranean area of the study. Moreover, the maps of changes in the burnt area reported by $\mathrm{Wu}$ et al. reveal the following spatially explicit trends within the EuroMediterranean area: LPJ-GUESS-SIMFIRE predicts slight increases in burnt area almost everywhere; in contrast, LPJmLSPITFIRE predicts decreases in burnt area for the southern half of the Iberian peninsula, the south of Bulgaria and the north of Greece (Macedonia region), while it predicts increases for the north of Iberian Peninsula, France, Italy, the western Balkans and the rest of Greece, and these increases are higher than with LPJ-GUESS-SIMFIRE. Hence, LPJmLSPITFIRE produces higher spatial variability.

To explain these opposite trends, the authors point out the divergent trends in fuel loads: LPJmL-SPITFIRE predicts an important decline in fuel loads in the Mediterranean area due to climate warming, which limits fire spread, whereas LPJGUESS-SIMFIRE predicts a slighter decrease in fuel loads largely offset by the increase in fire weather. Several differences can explain diverging fuel load trends, since the models do not treat fuel load estimation, fuel effects on fire and fire feedbacks on fuels in the same way. Noticeably, SIMFIRE is a simple model with few parameters, which could make it less sensitive to input conditions or feedbacks than SPITFIRE. LPJ-GUESS uses the FAPAR as a proxy for fuel load and continuity, while LPJ-mL estimates the litter fuels from the carbon pools of the DGVM. Moreover, according to $\mathrm{Wu}$ et al., SPITFIRE likely overestimates fire-induced feedbacks to vegetation composition and structure, as compared with SIMFIRE, because the two associated DGVMs represent the vegetation differently (see Sect. 2).

Khabarov et al. (2016) used a modelling framework similar to Migliavacca et al. (2013a), but with a non-dynamic (fixed) vegetation, which likely explains that the increase in burnt area was much larger than in other studies using DVGM coupled with a fire model.

Interestingly, a significant number of studies provide results for Spain or for the Iberian Peninsula, which is not the case for other countries. For Spain, Amatulli et al. (2013) found a drastic but likely unrealistic 8-fold increase by the end of the century, or a $93 \%$ increase per decade, under the A2 scenario. According to the authors, it is likely that the drought components of the FWI, which are not bounded, no longer reflect fire activity under the extreme climatic conditions that are projected for most of the Iberian Peninsula by the end of the century. Still for Spain, Vázquez de la Cueva et al. (2012) found a 51\% burnt area increase per decade under the A2 scenario. For the Iberian Peninsula, Sousa et al. (2015) projected a 23\% increase per decade up to the mid-century under the A1B scenario. Hence, the studies of Vázquez de la Cueva et al. (2012) and Sousa et al. (2015), which both use regression on weather variables, are compatible in order of magnitude, and predict a much lower increase than Amatulli et al. (2013), who instead used unbounded FWI components as predictors, which tends to confirm the overestimation of future increase in burnt area by the latter. In contrast, even when using the actual historical burnt area as a reference, we computed from Migliavacca et al. (2013a) data (A1B scenario) a $12 \%$ increase per decade only for the Iberian Peninsula. This low increase is qualitatively in line with the maps of burnt area changes reported by Wu et al. (2015) that show either slight increase (LPJ-GUESS-SIMFIRE) or both large increases and large decreases (LPJmL-SPITFIRE) across the Iberian Peninsula, as reported above. For a region of Spain (Catalonia), Turco et al. (2014) projected increased fire number but decreased burnt areas in Catalonia in the future. The burnt area model exhibited a negative sensitivity to antecedent (2year lag) seasonal (February to November) temperatures, which was selected as one of the predictors. According to the authors, this effect of antecedent weather was associated with fuel buildup, which, in a warm and dry climate, should be higher in seasons with higher precipitations and lower temperatures. The trend in burnt area would convey decreasing fuel load/ continuity under a warmer climate in an arid region. Also for Catalonia, Loepfe et al. (2012) used two simple models for fire number and burnt area based on yearly maxima of the DC to project future fire activity in three distinct sub-regions. They found similar relative increase in fire number $(20-23 \%$ per decade) in all sub-regions but contrasted relative increases (996\% per decade) in burnt areas: the currently wetter and cooler sub-region, with forests located at higher altitudes and infrequent fires, exhibited the highest relative increase. These results are thus, for burnt area, opposite to the findings of Turco et al. (2014). This makes sense since only seasonal drought drives seasonal fire activity in Loepfe et al., and it is expected to be more frequent and intense in the future, whereas in Turco et al., antecedent weather conditions can counterbalance the seasonal increase in fire danger through decreased fuel loads.

\section{References}

Abatzoglou JT, Williams AP, Barbero R (2019) Global emergence of anthropogenic climate change in fire weather indices. Geophys Res Lett 46(1):326-336. https://doi.org/10.1029/2018GLL080959

Ager AA, Preisler HK, Arca B, Spano D, Salis M (2014) Wildfire risk estimation in the Mediterranean area. Environmetrics 25:384-396. https://doi.org/10.1002/env.2269 
Aguado I, Chuvieco E, Borén R, Nieto H (2007) Estimation of dead fuel moisture content from meteorological data in Mediterranean areas. Applications in fire danger assessment. Int J Wildland Fire 16:390 397. https://doi.org/10.1071/WF06136

Amatulli G, Camia A, San-Miguel-Ayanz J (2013) Estimating future burned areas under changing climate in the EU-Mediterranean countries. Sci Total Environ 450:209-222. https://doi.org/10.1016/j. scitotenv.2013.02.014

Anderson SAJ (2009) Future options for fire behaviour modelling and fire danger rating in New Zealand. Proc R Soc Queensland 115:119 128

Arca B, Pellizzaro G, Duce P, Salis M, Bacciu V, Spano D, Ager A, Scoccimarro E (2012) Potential changes in fire probability and severity under climate change scenarios in Mediterranean areas. In: Spano D, Bacciu V, Salis M, Sirca C (eds) Modelling fire behaviour and risk. Nuova Stampa Color, Muros, pp 92-98

Arora VK, Boer GJ (2005) Fire as an interactive component of dynamic vegetation models. J Geophys Res Biogeosci 110. https://doi.org/10. 1029/2005JG000042

Bedia J, Herrera S, Camia A, Moreno JM, Gutiérrez JM (2014a) Forest fire danger projections in the Mediterranean using ENSEMBLES regional climate change scenarios. Clim Chang 122(1-2):185-199. https://doi.org/10.1007/s10584-013-1005-z

Bedia J, Herrera S, Gutiérrez JM (2014b) Assessing the predictability of fire occurrence and area burned across phytoclimatic regions in Spain. Nat Hazards Earth Syst Sci 14:53-66. https://doi.org/10. 5194/nhess-14-53-2014

Boberg F, Christensen JH (2012) Overestimation of Mediterranean summer temperature projections due to model deficiencies. Nat Clim Chang 2(6):433-436. https://doi.org/10.1038/nclimate1454

Bowman DM, Balch J, Artaxo P, Bond WJ, Cochrane MA, D'antonio CM, DeFries R, Johnston FH, Keeley JE, Krawchuck MA, Kull CA, Mack M, Moritz JE, Pyne S, Roos CI, Scott AC, Sodhi N, Swetnam TW (2011) The human dimension of fire regimes on Earth. J Biogeogr 38(12):2223-2236. https://doi.org/10.1111/j.1365-2699. 2011.02595.x

Bradstock RA (2010) A biogeographic model of fire regimes in Australia: current and future implications. Glob Ecol Biogeogr 19:145-158. https://doi.org/10.1111/j.1466-8238.2009.00512.x

Brotons L, Duane A (2019) Correspondence: uncertainty in climatevegetation feedbacks on fire regimes challenges reliable long-term projections of burnt area from correlative models. Fire 2(1):8 . https://doi.org/10.3390/fire2010008

Brotons L, Aquilué N, De Cáceres M, Fortin MJ, Fall A (2013) How fire history, fire suppression practices and climate change affect wildfire regimes in Mediterranean landscapes. PLoS One 8(5):e62392. https://doi.org/10.1371/journal.pone.0062392

Brown AA, Davis KP (1973) Fire danger rating. In: Forest fire: control and use, 2nd edn. Mac Graw Hill, New York, pp 217-259

Camia A, Amatulli G (2009) Weather factors and fire danger in the Mediterranean. In: Chuvecio E (ed) Earth observation of wildland fires in Mediterranean ecosystems. Springer, Berlin Heidelberg, pp $71-82$

Cannon AJ (2018) Multivariate quantile mapping bias correction: an Ndimensional probability density function transform for climate model simulations of multiple variables. Clim Dyn 50(1-2):31-49. https://doi.org/10.1007/s00382-017-3580-6

Carvalho A, Flannigan MD, Logan K, Gowman LM, Miranda AI, Borrego C (2010) The impact of spatial resolution on area burned and fire occurrence projections in Portugal under climate change. Clim Chang 98:177-197. https://doi.org/10.1007/s10584-0099667-2

Carvalho AC, Carvalho A, Martins H, Marques C, Rocha A, Borrego C, Viegas DX, Miranda AI (2011) Fire weather risk assessment under climate change using a dynamical downscaling approach. Environ
Model Softw 26(9):1123-1133. https://doi.org/10.1016/j.envsoft. 2011.03.012

Castro FX, Tudela A, Sebastià MT (2003) Modeling moisture content in shrubs to predict fire risk in Catalonia (Spain). Agric For Meteorol 116(1):49-59. https://doi.org/10.1016/S0168-1923(02)00248-4

Ceccato P, Leblon B, Chuvieco E, Flasse S, Carlson JD (2003) Estimation of live fuel moisture content. In: Chuvieco (ed) Wildland fire danger estimation and mapping: the role of remote sensing data, vol 4 . World Scientific, pp 63-90

Chatry C, Le Gallou J, Le Quentrec M, Lafitte J, Laurens D, Creuchet D, Grelu J (2010) Rapport de la mission interministérielle 'Changements climatiques et extension des zones sensibles aux feux de forêts'. Rapport Min. Alimentation Agriculture Pêche n 1796. (Paris)

Cheaib A, Badeau V, Boe J, Chuine I, Delire C, Dufrêne E, François C, Gritti ES, Legay M, Pagé C, Thuiller W, Viovy N, Leadley P (2012) Climate change impacts on tree ranges: model intercomparison facilitates understanding and quantification of uncertainty. Ecol Lett 15(6):533-544. https://doi.org/10.1111/j.1461-0248.2012.01764.x

Chelli S, Maponi P, Campetella G, Monteverde P, Foglia M, Paris E, Lolis A, Panagopoulos T (2015) Adaptation of the Canadian Fire Weather Index to Mediterranean forests. Nat Hazards 75:1795-1810. https:// doi.org/10.1007/s11069-014-1397-8

Christensen JH, Boberg F, Christensen OB, Lucas-Picher P (2008) On the need for bias correction of regional climate change projections of temperature and precipitation. Geophys Res Lett 35. https://doi.org/ 10.1029/2008GL035694

Clopet E, Regimbeau M (2009) Estimation de l'impact des incendies de forêt dans le domaine de l'eau et des incendies de forêt. Rapport d'étude final. http://www.side.developpement-durable.gouv.fr/ EXPLOITATION/DEFAULT/doc/IFD/IFD REFDOC 0505043/ Estimation-de-1-impact-du-changement-climatique-dans-ledomaine-de-1-eau-et-des-incendies-de-foret-. Accessed 20 June 2019

Costa R, Fraga H, Fernandes PM, Santos JA (2015) Implications of future bioclimatic shifts on Portuguese forests. Reg Environ Chang 17: 117-127. https://doi.org/10.1007/s10113-016-0980-9

Curt T, Frejaville T (2018) Wildfire policy in Mediterranean France: how far is it efficient and sustainable? Risk Anal 38(3):472-488. https:// doi.org/10.1111/risa.12855

DaCamara CC, Calado TJ, Ermida SL, Trigo IF, Amraoui M, Turkman KF (2014) Calibration of the Fire Weather Index over Mediterranean Europe based on fire activity retrieved from MSG satellite imagery. Int J Wildland Fire 23(7):945-958. https://doi.org/10.1071/ WF13157

Dowdy AJ, Mills GA, Finkele K, de Groot W (2010) Index sensitivity analysis applied to the Canadian Forest Fire Weather Index and the McArthur Forest Fire Danger Index. Met Apps 17:298-312. https:// doi.org/10.1002/met.170

Dury M, Hambuckers A, Warnant P, Henrot A, Favre E, Ouberdous M, François M (2011) Responses of European forest ecosystems to $21^{\text {st }}$ century climate: assessing changes in interannual variability and fire intensity. iForest 4:82-99. http://hdl.handle.net/2268/96370. Accessed 4 July 2018

Ehret U, Zehe E, Wulfmeyer V, Warrach-Sagi K, Liebert J (2012) HESS opinions "should we apply bias correction to global and regional climate model data?". Hydrol Earth Syst Sci 16:3391-3404. https://doi.org/10.5194/hess-16-3391-2012

Evin G, Curt T, Eckert N (2018) Has fire policy decreased the return period of the largest wildfire events in France? A Bayesian assessment based on extreme value theory. Nat Hazards Earth Syst Sci 18: 2641-2651. https://doi.org/10.5194/nhess-18-2641-2018

Faggian P (2018) Estimating fire danger over Italy in the next decade. Euro-Mediterr J Environ Integr 3:15-13. https://doi.org/10.1007/ s41207-018-0053-1 
Fernandes PM (2019) Variation in the Canadian fire weather index thresholds for increasingly larger fires in Portugal. Forests 10:838. https:// doi.org/10.3390/f10100838

Fernandes PM, Loureiro C (2013) Fine fuels consumption and $\mathrm{CO}_{2}$ emissions from surface fire experiments in maritime pine stands in northern Portugal. For Ecol Manag 291:344-356. https://doi.org/10. 1016/j.foreco.2012.11.037

Fernandes PM, Loureiro C, Guiomar N, Pezzatti GB, Manso FT, Lopes L (2014) The dynamics and drivers of fuel and fire in the Portuguese public forest. J Environ Manag 146:373-382. https://doi.org/10. 1016/j.jenvman.2014.07.049

Fernandes PM, Monteiro-Henriques T, Guiomar N, Loureiro C, Barros A (2016a) Bottom-up variables govern large-fire size in Portugal. Ecosystems 19:1362-1375. https://doi.org/10.1007/s10021-0160010-2

Fernandes PM, Barros AG, Pinto A, Santos JA (2016b) Characteristics and drivers of extremely large wildfires in the western Mediterranean Basin. J Geophys Res Biogeosci 121:2141-2157. https://doi.org/10.1002/2016JG003389

Flannigan MD, Krawchuk MA, de Groot WJ, Wotton BM, Gowman LM (2009) Implications of changing climate for global wildland fire. Int J Wildland Fire 18(5):483-507. https://doi.org/10.1071/WF08187

Flannigan M, Cantin AS, De Groot WJ, Wotton M, Newbery A, Gowman LM (2013) Global wildland fire season severity in the 21st century. For Ecol Manag 294:54-61 https://doi.org/10.1016/j.foreco.2012. 10.022

Flannigan MD, Wotton BM, Marshall GA, de Groot WJ, Johnston J, Jurko N, Cantin AS (2016) Fuel moisture sensitivity to temperature and precipitation: climate change implications. Clim Chang 134:5971. https://doi.org/10.1007/s10584-015-1521-0

Foley AM (2010) Uncertainty in regional climate modelling: a review. Prog Phys Geogr 34:647-670. https://doi.org/10.1177/ 0309133310375654

Fréjaville T, Curt T (2015) Spatiotemporal patterns of changes in fire regime and climate: defining the pyroclimates of south-eastern France (Mediterranean Basin). Clim Chang 129(1-2):239-251. https://doi.org/10.1007/s10584-015-1332-3

Ganatsas P, Antonis M, Marianthi T (2011) Development of an adapted empirical drought index to the Mediterranean conditions for use in forestry. Agric For Meteorol 151:241-250. https://doi.org/10.1016/ j.agrformet.2010.10.011

Ganteaume A, Camia A, Jappiot M, San-Miguel-Ayanz J, Long-Fournel L, Lampin C (2013) A review of the main driving factors of forest fire ignition over Europe. Environ Manag 51(3):651-662. https:// doi.org/10.1007/s00267-012-9961-Z

Good P, Moriondo M, Giannakopoulos C, Bindi M (2008) The meteorological conditions associated with extreme fire risk in Italy and Greece: relevance to climate model studies. Int J Wildland Fire 17: 155-165. https://doi.org/10.1071/WF07001

Haddeland I, Heinke J, Voß F, Eisner S, Chen C, Hagemann S, Ludwig F (2012) Effects of climate model radiation, humidity and wind estimates on hydrological simulations. Hydrol Earth Syst Sci 16:305318. https://doi.org/10.5194/hess-16-305-2012

Hanson CE, Palutikof JP (2005) Final report of Modelling the Impacts of Climate extremes (MICE) Project. Project number: EVK2-CT2001-00118

Hantson S, Lasslop G, Kloster S, Chuvieco E (2015) Anthropogenic effects on global mean fire size. Int J Wildland Fire 24:589-596. https://doi.org/10.1071/WF14208

Hantson S, Arneth A, Harrison SP, Kelley DI, Prentice IC, Rabin SS, Archibald S, Mouillot F, Arnold SR, Artaxo P, Bachelet D, Ciais P, Forrest M, Friedlingstein P, Hickler T, Kaplan JO, Kloster S, Knorr W, Lasslop G, Li F, Mangeon S, Melton JR, Meyn A, Sitch S, Spessa A, van der Werf GR, Voulgarakis A, Yue C (2016) The status and challenge of global fire modelling. Biogeosciences 13: 3359-3375. https://doi.org/10.5194/bg-13-3359-2016
Hawkins E, Sutton R (2009) The potential to narrow uncertainty in regional climate predictions. Bull Am Meteorol Soc 90(8):1095. https://doi.org/10.1175/2009BAMS2607.1

Hernandez C, Keribin C, Drobinski P, Turquety S (2015) Statistical modelling of wildfire size and intensity: a step toward meteorological forecasting of summer extreme fire risk. Ann Geophys 33: 1495-1506. https://doi.org/10.5194/angeo-33-1495-2015

Herrera S, Bedia J, Gutierrez J, Fernandez J, Moreno JM (2013) On the projection of future fire danger conditions with various instantaneous/mean-daily data sources. Clim Chang 118:827-840. https://doi.org/10.1007/s10584-012-0667-2

Hickler T, Vohland K, Feehan J, Miller PA, Smith B, Costa L, Giesecke T, Fronzek S, Carter TR, Cramer W, Kühn I, Sykes MT (2012) Projecting the future distribution of European potential natural vegetation zones with a generalized, tree species-based dynamic vegetation model. Glob Ecol Biogeogr 21:50-63. https://doi.org/10. $1111 / j .1466-8238.2010 .00613 . x$

Higuera PE, Abatzoglou JT, Littell JS, Morgan P (2015) The changing strength and nature of fire-climate relationships in the northern Rocky Mountains, USA, 1902-2008. PLoS One 10(6):e127563. https://doi.org/10.1371/journal.pone.0127563

Holsten A, Dominic AR, Costa L, Kropp JP (2013) Evaluation of the performance of meteorological forest fire indices for German federal states. For Ecol Manag 287:123-131. https://doi.org/10.1016/j. foreco.2012.08.035

Jolly WM, Johnson DM (2018) Pyro-ecophysiology: shifting the paradigm of live wildland fuel research. Fire 1(1):8. https://doi.org/10. 3390/fire 1010008

Jolly WM, Hadlow AM, Huguet K (2014) De-coupling seasonal changes in water content and dry matter to predict live conifer foliar moisture content. Int J Wildland Fire 23(4):480-489. https://doi.org/10.1071/ WF13127

Jolly WM, Cochrane MA, Freeborn PH, Holden ZA, Brown TJ, Williamson GJ, Bowman DM (2015) Climate-induced variations in global wildfire danger from 1979 to 2013. Nat Commun 6: 7537. https://doi.org/10.1038/ncomms8537

Kalabokidis K, Palaiologou P, Gerasopoulos E, Giannakopoulos C, Kostopoulou E, Zerefos C (2015) Effect of climate change projections on forest fire behavior and values-at-risk in southwestern Greece. Forests 6(6):2214-2240. https://doi.org/10.3390/f6062214

Karali A, Hatzaki M, Giannakopoulos C, Roussos A, Xanthopoulos G, Tenentes V (2014) Sensitivity and evaluation of current fire risk and future projections due to climate change: the case study of Greece. Nat Hazards Earth Sci 14(1):143-153. https://doi.org/10.5194/ nhess-14-143-2014

Keeley J, Syphard A (2016) Climate change and future fire regimes: examples from California. Geosciences 6:37. https://doi.org/10. 3390/geosciences6030037

Keeley JE, Bond WJ, Bradstock RA, Pausas JG, Rundel PW (2011) Fire in Mediterranean ecosystems: ecology, evolution and management. Cambridge University Press, Cambridge

Khabarov N, Krasovskii A, Obersteiner M, Swart R, Dosio A, SanMiguel-Ayanz J, Durrant T, Camia A, Migliavacca M (2016) Forest fires and adaptation options in Europe. Reg Environ Chang 16:21-30. https://doi.org/10.1007/s10113-014-0621-0

Knorr W, Lehsten V, Arneth A (2012) Determinants and predictability of global wildfire emissions. Atmos Chem Phys 12:6845-6861. https://doi.org/10.5194/acp-12-6845-2012

Knorr W, Kaminski T, Arneth A, Weber U (2013) Impact of human population density on fire frequency at the global scale. Biogeosci Discuss 10:15735-15778. https://doi.org/10.5194/bgd-10-157352013

Koutsias N, Xanthopoulos G, Founda D, Xystrakis F, Nioti F, Pleniou M, Mallinis G, Arianoutsou M (2013) On the relationships between forest fires and weather conditions in Greece from long-term 
national observations (1894-2010). Int J Wildland Fire 22(4):493507. https://doi.org/10.1071/WF12003

Kovats RS, Valentini R, Bouwer LM, Georgopoulou E, Jacob D, Martin E, Rounsevell M, Soussana JF (2014) Europe. In: Barros VR, Field CB, Dokken DJ, Mastrandrea MD, Mach KJ, Bilir TE, Chatterjee M, Ebi KL, Estrada YO, Genova RC, Girma B, Kissel ES, Levy AN, MacCracken, Mastrandrea PR, White LL (eds) Climate change 2014: impacts, adaptation, and vulnerability. Part B: regional aspects. Contribution of Working Group II to the Fifth Assessment Report of the Intergovernmental Panel on Climate Change

Krawchuk MA, Moritz MA, Parisien MA, Van Dorn J, Hayhoe K (2009) Global pyrogeography: the current and future distribution of wildfire. PLoS One 4(4):e5102. https://doi.org/10.1371/journal.pone. 0005102

Li D, Feng J, Xu Z, Yin B, Shi H, Qi J (2019) Statistical bias correction for simulated wind speeds over CORDEX-East Asia. Earth Space Sci 6:200-211. https://doi.org/10.1029/2018EA000493

Lindner M, Fitzgerald JB, Zimmermann NE, Reyer C, Delzon S, van der Maaten E, Schelhaas MJ, Eggers J, van der Maaten - Theunissen M, Suckow F, Psomas A, Poulter B, Hanewinkel M (2014) Climate change and European forests: What do we know, what are the uncertainties, and what are the implications for forest management? J Environ Manag 146:69-83. https://doi.org/10.1016/j.jenvman. 2014.07.030

Littell JS, McKenzie D, Peterson DL, Westerling AL (2009) Climate and wildfire area burned in western US ecoprovinces, 1916-2003. Ecol Appl 19(4):1003-1021. https://doi.org/10.1890/07-1183.1

Loepfe L, Martinez-Vilalta J, Piñol J (2012) Management alternatives to offset climate change effects on Mediterranean fire regimes in NE Spain. Clim Chang 115(3-4):693-707. https://doi.org/10.1007/ s10584-012-0488-3

Loepfe L, Rodrigo A, Lloret F (2014) Two thresholds determine climatic control of forest fire size in Europe and northern Africa. Reg Environ Chang 14(4):1395-1404. https://doi.org/10.1007/s10113013-0583-7

Lozano OM, Salis M, Ager AA, Arca B, Alcasena FJ, Monteiro AT, Finney MA, Del Giudice L, Scoccimarro E, Spano D (2017) Assessing climate change impacts on wildfire exposure in Mediterranean areas. Risk Anal 37(10):1898-1916. https://doi.org/ 10.1111/risa. 12739

Lung T, Dosio A, Becker W, Lavalle C, Bouwer LM (2013) Assessing the influence of climate model uncertainty on EU-wide climate change impact indicators. Clim Chang 120(1-2):211-227. https://doi.org/ 10.1007/s10584-013-0825-1

Maraun D (2016) Bias correcting climate change simulations-a critical review. Curr Clim Change Rep 2(4):211-220. https://doi.org/10. 1007/s40641-016-0050-x

Martínez-Fernández J, Chuvieco E, Koutsias N (2013) Modelling longterm fire occurrence factors in Spain by accounting for local variations with geographically weighted regression. Nat Hazards Earth Syst Sci 13:311-327. https://doi.org/10.5194/nhess-13-311-2013

Martin-StPaul N, Delzon S, Cochard H (2017) Plant resistance to drought depends on timely stomatal closure. Ecol Lett 20(11):1-23. https:// doi.org/10.1111/ele.12851

Matthews S (2014) Dead fuel moisture research: 1991-2012. Int J Wildland Fire 23:78-92. https://doi.org/10.1071/WF13005

McDowell N, Pockman WT, Allen CD, Breshears DD, Cobb N, Kolb T, Plaut J, Sperry J, West A, Williams DG, Yepez EA (2008) Mechanisms of plant survival and mortality during drought: why do some plants survive while others succumb to drought? New Phytol 178:719-739. https://doi.org/10.1111/j.1469-8137.2008. 02436.x

Migliavacca M, Dosio A, Camia A, Hobourg R, Houston-Durrant T, Kaiser JW, Khabarov N, Krasovskii AA, Marcolla B, San MiguelAyanz J, Ward DS, Cescatti A (2013a) Modeling biomass burning and related carbon emissions during the 21 st century in Europe. J
Geophys Res Biogeosci 118:1732-1747. https://doi.org/10.1002/ 2013JG002444

Migliavacca M, Dosio A, Kloster S, Ward DS, Camia A, Houborg R, Houston Durrant T, Khabarov N, Krasovskii AA, San MiguelAyanz J, Cescatti A (2013b) Modeling burned area in Europe with the Community Land Model: MODELING BURNED AREA IN EUROPE. J Geophys Res Biogeosci 118:265-279. https://doi.org/ $10.1002 /$ jgrg. 20026

Mitsopoulos I, Mallinis G, Arianoutsou M (2015) Wildfire risk assessment in a typical Mediterranean wildland-urban interface of Greece. Environ Manag 55(4):900-915. https://doi.org/10.1007/s00267014-0432-6

Moreira F, Viedma O, Arianoutsou M, Curt T, Koutsias N, Rigolot E, Barbati A, Corona P, Vaz P, Xanthopoulos G, Mouillot F, Bilgili E (2011) Landscape-wildfire interactions in southern Europe: implications for landscape management. J Environ Manag 92(10):2389 2402. https://doi.org/10.1016/j.jenvman.2011.06.028

Moreno MV, Conedera M, Chuvieco E, Pezzatti GB (2014) Fire regime changes and major driving forces in Spain from 1968 to 2010. Environ Sci Pol 37:11-22. https://doi.org/10.1016/j.envsci.2013. 08.005

Moriondo M, Good P, Durao R, Bindi M, Giannakopoulos C, Corte-Real J (2006) Potential impact of climate change on fire risk in the Mediterranean area. Clim Res 31(1):85-95. https://doi.org/10. 3354/cr031085

Moritz MA, Parisien MA, Batllori E, Krawchuk MA, Van Dorn J, Ganz DJ, Hayhoe K (2012) Climate change and disruptions to global fire activity. Ecosphere 3(6):1-22. https://doi.org/10.1890/ES11-00345. 1

Mouillot F, Rambal S, Joffre R (2002) Simulating climate change impacts on fire frequency and vegetation dynamics in a Mediterranean-type ecosystem. Glob Chang Biol 8(5):423-437. https://doi.org/10.1046/ j.1365-2486.2002.00494.x

Palheiro PM, Fernandes P, Cruz MG (2006) A fire behaviour-based fire danger classification for maritime pine stands: comparison of two approaches. For Ecol Manag 234(S1):S54. https://doi.org/10.1016/j. foreco.2006.08.075

Pausas JG (2004) Changes in fire and climate in the eastern Iberian Peninsula (Mediterranean basin). Clim Chang 63(3):337-350. https://doi.org/10.1023/B:CLIM.0000018508.94901.9c

Pausas JG, Fernández-Muñoz S (2012) Fire regime changes in the Western Mediterranean Basin: from fuel-limited to drought-driven fire regime. Clim Chang 110(1-2):215-226. https://doi.org/10. 1007/s10584-011-0060-6

Pausas JG, Paula S (2012) Fuel shapes the fire-climate relationship: evidence from Mediterranean ecosystems. Glob Ecol Biogeogr 21(11): 1074-1082. https://doi.org/10.1111/j.1466-8238.2012.00769.x

Pellizzaro G, Cesaraccio C, Duce P, Ventura A, Zara P (2007) Relationships between seasonal patterns of live fuel moisture and meteorological drought indices for Mediterranean shrubland species. Int J Wildland Fire 16(2):232-241. https://doi.org/10.1071/ WF06081

Pellizzaro G, Ventura A, Arca B, Arca A, Duce P, Bacciu V, Spano D (2010) Estimating effects of future climate on duration of fire danger season in Sardinia. In: Viegas DX (ed) Proceedings of VI International Forest Fire Research Conference, 15-18, November 2010, University of Coimbra, Coimbra, Portugal, Session BP11 Climate and Fire Meteorology. Coimbra, $8 \mathrm{pp}$

Pereira MG, Malamud BD, Trigo RM, Alves PI (2011) The history and characteristics of the 1980-2005 Portuguese rural fire database. Nat Hazards Earth Syst Sci 11(12):3343-3358. https://doi.org/10.5194/ nhess-11-3343-2011

Pimont F, Ruffault J, Martin-StPaul NK, Dupuy JL (2019) Why is the effect of live fuel moisture content on fire rate of spread underestimated in field experiments in shrublands? Int J Wildland Fire 28:127-137. https://doi.org/10.1071/WF18091 
Piñol J, Terradas J, Lloret F (1998) Climate warming, wildfire hazard, and wildfire occurrence in coastal eastern Spain. Clim Chang 38(3):345357. https://doi.org/10.1023/A:1005316632105

Rabin SS, Melton JR, Lasslop G, Bachelet D, Forrest M, Hantson S, Kaplan JO, Li F, Mangeon S, Ward DS, Yue C, Arora VK, Hickler T, Kloster S, Knorr W, Nieradzik L, Spessa A, Folberth GA, Sheehan T, Voulgarakis A, Kelley DI, Prentice IC, Sitch S, Harrison S, Arneth A (2017) The Fire Modeling Intercomparison Project (FireMIP), phase 1: experimental and analytical protocols with detailed model descriptions. Geosci Model Dev 10:11751197. https://doi.org/10.5194/gmd-10-1175-2017

Resco de Dios V, Fellows AW, Nolan RH, Boer MM, Bradstock RA, Domingo F, Goulden ML (2015) A semi-mechanistic model for predicting the moisture content of fine litter. Agric For Meteorol 203:64-73. https://doi.org/10.1016/j.agrformet.2015.01.002

Rossa C, Fernandes P (2018) Live fuel moisture content: the 'pea under the mattress' of fire spread rate modeling? Fire 1:43. https://doi.org/ 10.3390/fire 1030043

Ruffault J, Mouillot F (2015) How a new fire-suppression policy can abruptly reshape the fire-weather relationship. Ecosphere 6(10):119. https://doi.org/10.1890/ES15-00182.1

Ruffault J, Moron V, Trigo RM, Curt T (2016) Objective identification of multiple large fire climatologies: an application to a Mediterranean ecosystem. Environ Res Lett 11(7):075006. https://doi.org/10.1088/ 1748-9326/11/7/075006

Ruffault J, Martin-StPaul N, Pimont F, Dupuy JL (2018) How well do meteorological drought indices predict live fuel moisture content (LFMC)? An assessment for wildfire research and operations in Mediterranean ecosystems. Agric For Meteorol 262:391-401. https://doi.org/10.1016/j.agrformet.2018.07.031

Salis M, Ager AA, Finney MA, Arca B, Spano D (2014) Analyzing spatiotemporal changes in wildfire regime and exposure across a Mediterranean fire-prone area. Nat Hazards 71(3):1389-1418. https://doi.org/10.1007/s11069-013-0951-0

San-Miguel-Ayanz J, Moreno JM, Camia A (2013) Analysis of large fires in European Mediterranean landscapes: lessons learned and perspectives. For Ecol Manag 294:11-22. https://doi.org/10.1016/j.foreco. 2012.10.050

San-Miguel-Ayanz J, Durrant T, Boca R, Libertà G, Branco A, de Rigo D, Ferrari D, Maianti P, Artés Vivancos T, Costa H, Lana F, Löffler P, Nuijten D, Ahlgren AC, Leray T (2018) Forest fires in Europe, Middle East and North Africa 2017. EUR 29318 EN, ISBN 97892-79-92831-4. https://doi.org/10.2760/663443

Scholze M, Knorr W, Arnell NW, Prentice IC (2006) A climate-change risk analysis for world ecosystems. Proc Natl Acad Sci 103:1311613120. https://doi.org/10.1073/pnas.0601816103

Seidl R, Fernandes PM, Fonseca TF, Gillet F, Jönsson AM, Merganičová K, Netherer S, Arpaci A, Bontemps JD, Bugmann H, GonzálezOlabarria JR, Lasch P, Meredieu C, Moreira F, Schelhaas MJ, Mohren F (2011) Modelling natural disturbances in forest ecosystems: a review. Ecol Model 222:903-924. https://doi.org/10.1016/j. ecolmodel.2010.09.040

Silva JM, Moreno MV, Le Page Y, Oom D, Bistinas I, Pereira JMC (2019) Spatiotemporal trends of area burnt in the Iberian Peninsula, 1975-2013. Reg Environ Chang 19(2):515-527. https://doi.org/10.1007/s10113-018-1415-6

Sousa PM, Trigo RM, Pereira MG, Bedia J, Gutiérrez JM (2015) Different approaches to model future burnt area in the Iberian Peninsula. Agric For Meteorol 202:11-25. https://doi.org/10.1016/ j.agrformet.2014.11.018

Thonicke K, Spessa A, Prentice IC, Harrison SP, Dong L, CarmonaMoreno C (2010) The influence of vegetation, fire spread and fire behaviour on biomass burning and trace gas emissions: results from a process-based model. Biogeosciences 7:1991-2011. https://doi. org/10.5194/bg-7-1991-2010

Turco M, Sanna A, Herrera S, Llasat MC, Gutiérrez JM (2013a) Large biases and inconsistent climate change signals in ENSEMBLES regional projections. Clim Chang 120(4):859-869. https://doi.org/ 10.1007/s10584-013-0844-y

Turco M, Llasat MC, von Hardenberg J, Provenzale A (2013b) Impact of climate variability on summer fires in a Mediterranean environment (northeastern Iberian Peninsula). Clim Chang 116(3-4):665-678. https://doi.org/10.1007/s10584-012-0505-6

Turco M, Llasat MC, Tudela A, Castro X, Provenzale A (2013c) Brief communication decreasing fires in a Mediterranean region (1970 2010, NE Spain). Nat Hazards Earth Syst Sci 13(3):649-652. https://doi.org/10.5194/nhess-13-649-2013

Turco M, Llasat MC, von Hardenberg J, Provenzale A (2014) Climate change impacts on wildfires in a Mediterranean environment. Clim Chang 125(3-4):369-380. https://doi.org/10.1007/s10584-014$1183-3$

Turco M, Bedia J, Di Liberto F, Fiorucci P, von Hardenberg J, Koutsias N, Llasat MC, Xystrakis F, Provenzale A (2016) Decreasing fires in Mediterranean Europe. PLoS One 11(3):e0150663. https://doi.org/ 10.1371/journal.pone.0150663

Turco M, von Hardenberg J, AghaKouchak A, Llasat MC, Provenzale A, Trigo RM (2017) On the key role of droughts in the dynamics of summer fires in Mediterranean Europe. Sci Rep 7(1):81. https://doi. org/10.1038/s41598-017-00116-9

Turco M, Rosa-Cánovas JJ, Bedia J, Jerez S, Montávez JP, Llasat MC, Provenzale A (2018) Exacerbated fires in Mediterranean Europe due to anthropogenic warming projected with non-stationary climatefire models. Nat Commun 9(1):3821. https://doi.org/10.1038/ s41467-018-06358-z

Van Wagner CE (1974) Structure of the Canadian Forest Fire Weather Index. Environment Canada, Canadian Forestry Service, Petawawa Forest Experiment Station, Chalk River, Ontario. Departmental Publication $1333.49 \mathrm{p}$

Van Wagner CE (1987) Development and structure of the Canadian Forest Fire Weather Index System. Canadian Forestry Service, Headquarters, Ottawa. Forestry Technical Report 35. $35 \mathrm{p}$

Vázquez de la Cueva A, Quintana JR, Cañellas I (2012) Fire activity projections in the SRES A2 and B2 climatic scenarios in peninsular Spain. Int J Wildland Fire 21:653-665. https://doi.org/10.1071/ WF11013

Vázquez A, Climent JM, Casais L, Quintana JR (2015) Current and future estimates for the fire frequency and the fire rotation period in the main woodland types of peninsular Spain: a case-study approach. For Syst 24(2):031. https://doi.org/10.5424/fs/201524206454

Vicente-Serrano SM, Beguería S, López-Moreno JI (2010) A multiscalar drought index sensitive to global warming: the standardized precipitation evapotranspiration index. J Clim 23(7):1696-1718. https:// doi.org/10.1175/2009JCLI2909.1

Vicente-Serrano SM, Gouveia C, Camarero JJ, Begueria S, Trigo R, Lopez-Moreno JI, Azorin-Molina C, Pasho E, Lorenzo-Lacruz J, Revuelto J, Moran-Tejeda E, Sanchez-Lorenzo A (2013) Response of vegetation to drought time-scales across global land biomes. Proc Natl Acad Sci 110:52-57. https://doi.org/10.1073/pnas.1207068110

Viegas DX, Pinol J, Viegas MT, Ogaya R (2001) Estimating live fine fuels moisture content using meteorologically-based indices. Int J Wildland Fire 10(2):223-240. https://doi.org/10. 1071/WF01022

Volaire F (2018) A unified framework of plant adaptive strategies to drought: crossing scales and disciplines. Glob Chang Biol 24: 2929-2938. https://doi.org/10.1111/gcb.14062 
Vrac M, Friederichs P (2015) Multivariate - intervariable, spatial, and temporal—bias correction. J Clim 28(1):218-237. https://doi.org/ 10.1175/JCLI-D-14-00059.1

Wu M, Knorr W, Thonicke K, Schurgers G, Camia A, Arneth A (2015) Sensitivity of burned area in Europe to climate change, atmospheric $\mathrm{CO}_{2}$ levels, and demography: a comparison of two fire-vegetation models. J Geophys Res Biogeosci 120(11):2256-2272. https://oi. org/10.1002/2015JG003036
Yebra M, Dennison PE, Chuvieco E, Riaño D, Zylstra P, Hunt ER, Danson FM, Qi Y, Jurdao S (2013) A global review of remote sensing of live fuel moisture content for fire danger assessment: moving towards operational products. Remote Sens Environ 136: 455-468. https://doi.org/10.1016/j.rse.2013.05.02

Publisher's note Springer Nature remains neutral with regard to jurisdictional claims in published maps and institutional affiliations. 